\title{
A Characterization of Optimal Feasible Tax Mechanism
}

\author{
Byungchae Rhee* \\ Department of Economics \\ Pennsylvania State University
}

May, 2004

\begin{abstract}
In this paper, we study the following question: For a public good economy where the provision of public goods is to be financed by property taxes collected from individuals, what is the optimal feasible tax mechanism when a social planner is relatively uninformed of the properties of the individuals? Using a Bayesian model, we provide the full characterization of the optimal feasible tax mechanism with two agents and its properties. We find that (i) when the expected total endowment of the economy is relatively low enough or high enough, the incentive compatibility constraint does not bind so that first best taxation can be obtained; (ii) the second best feasible tax mechanism requires a poor agent to pay relatively more than a rich agent, that is, it is regressive; and (iii) the optimal feasible tax mechanism is increasing in the sense that the agent's tax payment increases with his endowment. For the case of more than two agents, under certain mild assumptions we give some partial results similar to (i) and (ii) above. In addition, we find the optimal feasible tax mechanism for the corresponding infinitely large economy.
\end{abstract}

Keywords: optimal taxation, feasibility, incentive compatibility, informational rent, second best JEL classification: H21, D71, D82

\section{Introduction}

This paper is motivated by a practical property or income taxation problem: For a public good economy where the provision of public goods is to be financed by property taxes collected from individuals, what is the optimal feasible tax mechanism when a social planner is relatively uninformed of the properties of the individuals? ${ }^{1}$ In this case, the problem is that the social planner has to take into account not only the individuals' incentive to report their wealth truthfully, but also the individual feasibility of the designed tax schedule in the sense that each individual's tax payment

* I thank Professor Tomas Sjöström, my advisor, for his invaluable guidance and comments. I also thank Professors Kalyan Chatterjee, Steven Huddart, James Jordan, and Neil Wallace for their helpful comments. Of course, all remaining errors are mine. Contact Information: 608 Kern Graduate Building, University Park, PA 16802. E-mail: brhee@psu.edu

1 Some authors use the term interim efficient instead of optimal to emphasize the informational structure of their model. In this paper, we choose optimal and use second best if necessary to distinguish such a situation where the optimal tax mechanism is not first best. Also, throughout the paper, we will use the terms wealth, endowment, property or income of an agent interchangeably since they have the same meaning, the amount of resources the agent has initially. 
should be consistent with their ability to pay. In particular, this kind of problem, optimal private provision of public goods, is frequently observed in a small economy such as a club or village. ${ }^{2}$ Consider the following example. Two thieves, Ali and Baba, want to build a door for their treasure cave. The quality of the door depends on the total contributions they make. Suppose that Ali is relatively rich and has $\$ 200$, and Baba is relatively poor and has $\$ 100$, but that none of them knows how much the other has. A social planner, who does not know how much Ali and Baba have, asks them to report their wealth in order to determine their contributions (taxes). What is the optimal feasible tax mechanism that maximizes the expected sum of utilities? If the social planner wants to collect $\$ 300$ for the door-building, she cannot impose $\$ 150$ to each of the two thieves because it is not (individually) feasible to Baba.

The theory of optimal taxation has a long history. Since the seminal work by Mirrlees [1971], the optimal taxation literature has studied the incentive aspect of a tax mechanism and established many characterization results under a variety of economic situations. ${ }^{3}$ Mirrlees [1971] considers a labor income taxation problem for an infinitely large economy and studies the optimality of redistributive taxation when each individual has private information about his own productivity. He shows that the redistributive tax mechanism is subject to suboptimality due to the informational asymmetry between the public policy authority and the individuals. This situation is now well understood as a second best taxation. Following Mirrlees [1971], many authors have analyzed a trade-off between efficiency and equity of optimal income taxation. Other authors have studied the optimal taxation problem from the implementation perspective (Guesnerie [1995] and Piketty [1993] among others). However, most of these works have assumed that there is a continuum of individuals and the tax schedule depends on an observable variable such as labor income so that there are no individual feasibility or bankruptcy problems.

Implementation (or mechanism design) theory, pioneered by Hurwicz [1972] and Maskin [1999], studies the implementability of various social choice rules and the characterization of the implementing mechanisms under different environments and informational assumptions. ${ }^{4}$ Most of results in this literature, however, assume that the set of feasible outcomes is fixed and common knowledge so that this set does not depend on the realization of the economic environment. This is a quite restrictive assumption, in particular, when agents have private information about their own endowments or production technologies. If a social planner is relatively uninformed of the realization of agents' endowments, she has to consider the feasibility problem when designing an implementing mechanism. The first study to explicitly tackle this type of feasibility problem is Hurwicz, Maskin and Postlewaite [1995]. ${ }^{5}$ They considered the feasible implementation problem under complete information in which a social planner does not know the realization of agents' endowments or production sets. Following them, there have been some extensions of their model to incomplete information cases. ${ }^{6}$ However, those results have mainly focused on the implementability

\footnotetext{
2 Fund-rasing is another example of this problem. See, for example, Andreoni [1998].

For a survey of modern optimal taxation theory, see Stiglitz [1985].

For some recent surveys, see, e.g., Jackson [2000a, b], Palfrey [2002] and Maskin and Sjöström [2002].

The earlier version of this paper has been circulated since 1979.

See for example Hong [1996, 1998] and Tian [1999]. See also Dagan, Serreno, and Volij [1999], in which they study the feasible implementation of a given taxation method which embodies the socially optimal tax level. However, their work considers the taxation problem from the equity point of view so that the total amount of taxes to be collected is exogenously given. In contrast, our model deals with the efficiency of a tax mechanism which endogenously determines the each agent's tax payment as well as the total amount of taxes.
} 
of a general social choice rule, but not on the efficiency of the implementing mechanism. Such an efficiency problem has been a major subject in optimal taxation theory.

In this paper, we employ the so-called "endowment game" created by Hurwicz, Maskin and Postlewaite [1995] to model the optimal feasible taxation problem of a public good economy with a finite number of agents. That is, using a Bayesian model, we set up the maximization problem of a utilitarian social planner who is relatively uninformed of the agents' endowments. Since the number of agents in the economy is finite, each agent's tax payment will be affected not only by his own endowment not also by the others' endowments.

We first consider the case of two agents and two potential types, and fully characterize its solution. Also, we can illustrate this solution graphically due to the low dimensionality of the problem. The four main results of this paper are as follows. First, if the expected total endowment of the economy is relatively low enough or high enough, then first best feasible taxation can be obtained. This result is due to the fact that the incentive compatibility constraint does not bind at the corresponding first best feasible tax schedules when the economy is relatively poor or rich. Second, for the cases in which the incentive compatibility constraint does bind, the optimal feasible tax mechanism imposes a high tax rate on a poor agent when his neighbor is rich. The intuition behind this regressive taxation is that levying a tax on the poor agent does not cause an incentive problem so that the social planner, who does not mind which agent pays how much proportion of the total taxes, prefers to impose as much tax as possible on the poor agent rather than his rich neighbor who may request an informational rent as a reward for the revelation of his type. Third, the optimal feasible tax schedule is increasing in the sense that the tax payment of an agent is increasing in his endowment. Fourth, we conduct a comparative statics analysis on how the optimal feasible tax mechanism responds to a change in the initial parameter values. We first study the responses to a change in the probability distribution of endowment analytically, and then to a change in endowment parameters by means of simulation. In essence, these analyses show how each agent's tax payment depends on the incentive compatibility constraint and the relative size of low endowment.

As a natural extension, we consider the case of more than two agents. Although it is impossible to fully describe the optimal feasible tax mechanism for this case due to its high dimensionality and abundance of corner solutions, we obtain some partial results similar to those of the two-agent case under certain mild assumptions. In addition, we find the optimal feasible tax mechanism for the corresponding infinitely large economy, where the tax payment of an agent is always equal to the amount of the low endowment.

Finally, we would like to mention the two features of our model that distinguish it from the previous literature on public goods. Our model considers the continuous provision of public goods under incomplete information. There is a huge literature on mechanism design and public economics which analyzes public good economies. However, most of the models in this literature have dealt with the discrete (in fact, binary) provision of public goods. ${ }^{7}$ Although this discreteness makes the models mathematically simple and tractable, ${ }^{8}$ it is a restrictive assumption. In our model, the provision of public goods is continuous because it is determined directly by the total amount

\footnotetext{
$7 \quad$ See, for example, D'Aspremont and Gérard-Varet [1979], Laffont and Maskin [1979], and Gradstein [1994]. See also Groves and Ledyard [1987].

8 One of many advantages that the discreteness assumption brings about is to make the individual utility depend linearly on the provision of public goods.
} 
of taxes according to a constant returns to scale technology. ${ }^{9}$ Another feature of our model is the direct linkage between taxes and level of provision of public goods. For standard models in the implementation literature, for example D'Aspremont and Gérard-Varet [1979] and Laffont and Maskin [1979], there are little such a linkage, but mainly redistributive transfers among the agents, which are used to resolve incentive problems. To this point, our model is closely related the theory of private provision of public goods where collected taxes and level of provision of public goods are explicitly related.

The remainder of this paper is organized as follows. In Section 2, we present the model for a public good economy. In Section 3, we fully characterize the optimal feasible tax schedule for the economy with two agents and two possible types. Using the characterization results, in Section 4, we discuss the properties of the optimal mechanism and provide some comparative statics analyses. As an extension, we consider the case of more than two agents in Section 5. In Section 6, we give concluding remarks and future research agenda.

\section{The Model}

\subsection{The Economy}

Consider a public good economy with $n$ agents, $2 \leqq n<\infty .{ }^{10}$ Let $N=\{1, \ldots, n\}$ denote the set of agents. There is one private good $x \in \mathbb{R}_{+}$and one pure public good $y \in \mathbb{R}_{+}$, where the private good can be used to produce the public good according to a constant returns to scale technology. Without loss of generality, we normalize the production technology such that one unit of private good can be transformed into one unit of public good. Each agent $i \in N$ has the same quasilinear von Neumann-Morgenstern utility function $u$ on $\mathbb{R}_{+}^{2}$,

$$
u\left(x_{i}, y\right)=\log y+x_{i}
$$

where $x_{i}$ is the consumption of private good by agent $i$. Initially, each agent $i$ is endowed with private good $\omega_{i} \in\left\{\omega_{L}, \omega_{H}\right\}$ only, where $0 \leqq \omega_{L}<\omega_{H}<\infty .{ }^{11}$ Agent $i$ is called poor when $\omega_{i}=\omega_{L}$ and rich when $\omega_{i}=\omega_{H}$. Let

$$
\Omega=\left\{\left(\omega_{L}, \omega_{H}\right) \in \mathbb{R}_{+}^{2}: \omega_{L}<\omega_{H}\right\}
$$

denote the set of all possible pairs of initial endowments.

The information structure of this economy follows a standard incomplete information (Bayesian) model. The primitives of the economy are common knowledge, whereas each agent has private information about his own endowment. That is, agent $i$ knows the realization of his own endowment $\omega_{i}$ and the initial probability distribution of the other agents' endowments, but does not know

$9 \quad$ Ledyard and Palfrey [1999] employ a model that allows continuous public goods provision. However, under their assumptions of linear production and risk-neural preferences, it is equivalent to a discrete one. Also, Bergstrom, Blume, and Varian [1986] study a continuous model, but their model assumes complete information.

10 The case where there is only one agent in the economy is trivial. The case where $n=\infty$ will be discussed in Section 5.3 .

11 In this paper, each agent's initial endowment may be interpreted as a portion of his total wealth above the subsistence level. Thus, it can be called the agent's taxable wealth for the provision of public goods. This interpretation will be made clear in Section 4.1. 
the realizations of the other agents' endowments $\omega_{-i} \cdot{ }^{12}$ Agents' endowments are independently distributed according to

$$
\operatorname{Pr}\left(\omega_{i}=\omega_{L}\right)=p \in(0,1) \quad \forall i \in N .
$$

Thus, an economic environment is equivalent to the realization of $\omega=\left(\omega_{1}, \ldots, \omega_{n}\right)$.

\subsection{The Tax Mechanism}

A tax mechanism consists of message spaces $M_{i}$ for each agent $i \in N$, and an outcome function $f$ which maps each message profile $m \in M \equiv \prod_{i=1}^{n} M_{i}$ into agents' tax burdens $t(m)=$ $\left(t_{1}(m), \ldots, t_{n}(m)\right) \in \mathbb{R}_{+}^{n}$ and public good production $y ; f: m \mapsto(t(m), y(m))$. The constant returns to scale technology implies that $y(m) \leqq \sum_{i=1}^{n} t_{i}(m)$ for all $m \in M$, but without loss of generality, we can assume that the equality always holds since no taxes will be wasted. ${ }^{13}$ Hence, we have the following simple definition.

Definition 2.1 (Tax Mechanism and Schedule) $A$ tax mechanism $\Gamma$ is defined as $\Gamma=\langle M, t\rangle$, where $t: M \rightarrow \mathbb{R}_{+}^{n}$ is called a tax schedule.

Given a tax mechanism $\Gamma=\langle M, t\rangle$, let $s_{i}:\left\{\omega_{L}, \omega_{H}\right\} \rightarrow M_{i}$ denote the strategy (report) of agent $i$. By the Revelation Principle (see Myerson [1979]), we are able to restrict our attention to a direct incentive compatible tax mechanism. Thus, we assume that $M_{i}=\left\{\omega_{L}, \omega_{H}\right\}$ for each $i \in N$. The expected utility of agent $i$ when his endowment is $\omega_{i}$ and he reports $s_{i}$, assuming the other agents are truthful, is

$$
\begin{aligned}
U_{i}\left(s_{i} \mid \omega_{i}, t\right) & =\mathbb{E}_{\omega_{-i}}\left[u_{i}\left(\omega_{i}-t_{i}\left(s_{i}, \omega_{-i}\right), \sum_{j=1}^{n} t_{j}\left(s_{i}, \omega_{-i}\right)\right) \mid \omega_{i}\right] \\
& =\mathbb{E}_{\omega_{-i}}\left[\log \left(\sum_{j=1}^{n} t_{j}\left(s_{i}, \omega_{-i}\right)\right)+\left(\omega_{i}-t_{i}\left(s_{i}, \omega_{-i}\right)\right) \mid \omega_{i}\right] .
\end{aligned}
$$

In this paper, we make two assumptions which a tax mechanism should satisfy. First, following Hurwicz, Maskin, and Postlewaite [1995], we employ the no exaggeration assumption.

Assumption 2.2 (No Exaggeration) For each $i \in N, s_{i}\left(\omega_{i}\right) \leqq \omega_{i}$.

That is, no agent is allowed to overstate his endowment when reporting. ${ }^{14}$ This assumption partially relieves the informational disadvantage of the social planner. Another assumption is the anonymity of a tax mechanism: A tax schedule should not be affected by the change of agents' names. ${ }^{15}$ More specifically, this includes two conditions. First, an agent's tax payment should not be affected by

$\overline{12}$ Notational convention applies here, that is, given a vector $a=\left(a_{1}, \ldots, a_{n}\right) \in A=\prod_{i=1}^{n} A_{i}$,

$$
a_{-i}=\left(a_{1}, \ldots, a_{i-1}, a_{i+1}, \ldots, a_{n}\right) \in A_{-i}=\prod_{j \neq i} A_{j}, \quad \text { and } a=\left(a_{i}, a_{-i}\right)
$$

13 This property may be viewed as a budget-balancedness. Compare with the Clarke-Groves mechanism where budget-balancedness is usually not satisfied, see Clarke [1971] and Groves [1973].

14 It may be assumed that each agent is asked to put his report on the table.

15 This assumption must hold for every society where taxation is based on a democratic process. 
the change of order in the other agents' reports as long as the distribution of their reports remains the same. Second, any two agents' tax payments should be the same if they report the same endowment with other things being equal. Formally,

Assumption 2.3 (Anonymity) For all $i, j \in N$,

i. $t_{i}\left(s_{i}, s_{-i}\right)=t_{i}\left(s_{i}, \sigma\left(s_{-i}\right)\right)$,

ii. $s_{i}=s_{j} \Longrightarrow t_{i}\left(s_{i}, s^{\prime}\right)=t_{j}\left(s_{j}, s^{\prime}\right) \quad \forall s^{\prime} \in\left\{\omega_{L}, \omega_{H}\right\}^{n-1}$,

where $\sigma\left(s_{-i}\right)$ is a permutation of $s_{-i}$.

Under the anonymity assumption, let $t_{L,(n-k) L,(k-1) H}$ denote an agent's tax payment when he and $(n-k)$ of the other agents report $\omega_{L}$ and the remaining $(k-1)$ agents report $\omega_{H}, k=1, \ldots, n$. Define $t_{H,(n-k) L,(k-1) H}$ similarly. Then, we can express a tax schedule as

$$
t=\left(\left(t_{L,(n-k) L,(k-1) H}\right)_{k=1}^{n},\left(t_{H,(n-k) L,(k-1) H}\right)_{k=1}^{n}\right) .
$$

Since we are considering a direct mechanism, we simply identify a (direct) tax mechanism $\Gamma=\langle M, t\rangle$ with a tax schedule $t$ in this paper.

To state the social planner's problem, we need to look at three properties that a tax mechanism should satisfy: Feasibility, Incentive Compatibility, and Individual Rationality. First, feasibility, one of the most important concepts in this paper, implies that no tax mechanism should impose more than the announced endowment. ${ }^{16}$ That is,

Definition 2.4 (Feasibility) A tax mechanism $t$ is feasible if for all $k=1, \ldots, n$,

$$
0 \leqq t_{L,(n-k) L,(k-1) H} \leqq \omega_{L} \text { and } 0 \leqq t_{H,(n-k) L,(k-1) H} \leqq \omega_{H}
$$

Throughout this paper, we require all tax mechanisms considered to be feasible. Second, by the Revelation Principle, we consider an incentive compatible tax mechanism only.

Definition 2.5 (Incentive Compatibility: IC) A tax mechanism t is (Bayesian) incentive compatible if for all $i \in N$,

$$
U_{i}\left(\omega_{H} \mid \omega_{H}, t\right) \geqq U_{i}\left(\omega_{L} \mid \omega_{H}, t\right) .
$$

Note that due to the no exaggeration assumption, the incentive compatibility of a tax mechanism for this economy is just one-directional; the inequality $U_{i}\left(\omega_{L} \mid \omega_{L}, t\right) \geqq U_{i}\left(\omega_{H} \mid \omega_{L}, t\right)$ is meaningless. Third, to make the agents participate in this public good economy, we need to make assumptions as to what will happen if an agent does not participate. Notice that we have to distinguish between the situations in which an agent does not want to report his endowment and in which an agent wants to leave the economy or denies to pay the imposed tax. In the former case, we assume that the social planner can impose a tax on the agent as if he were to report that his endowment is $\omega_{L} \cdot{ }^{17}$ Under this assumption, the expected utility of agent $i$ who did not report is $U_{i}\left(\omega_{L} \mid \omega_{H}, t\right)$ if his endowment is $\omega_{H}$, or $U_{i}\left(\omega_{L} \mid \omega_{L}, t\right)$ if his endowment is $\omega_{L}$. Since only incentive compatible

16 In this sense, the feasibility can also be called no-bankruptcy.

17 This kind of tax enforcement scheme seems well established in reality. Implicit or explicit membership fee in a club is one of the examples. 
tax mechanisms are considered, agent $i$ who reports his endowment will obtain $U_{i}\left(\omega_{H} \mid \omega_{H}, t\right)$ if his endowment is $\omega_{H}$, or $U_{i}\left(\omega_{L} \mid \omega_{L}, t\right)$ if his endowment is $\omega_{L}$. Thus, by inequality (1), every agent will report his endowment, which makes the individual rationality condition redundant in this model. In the latter case, we assume that the social planner can prevent the agent from enjoying public good by, for example, expulsion from the economy. ${ }^{18}$ Under this assumption, the expected utility of the agent is $u\left(x_{i}, 0\right)=-\infty, \forall x_{i} \in \mathbb{R}_{+}$. Thus, the individual rationality constraint becomes redundant, too. As a result, we can ignore individual rationality by the above two assumptions.

Finally, we add one more definition for a tax mechanism.

Definition 2.6 (Increasingness) A tax mechanism $t$ is increasing if for all $k=1, \ldots, n$,

$$
t_{L,(n-k) L,(k-1) H} \leqq t_{H,(n-k) L,(k-1) H} .
$$

That is, a tax mechanism is increasing if an agent's tax payment is increasing with his endowment.

\subsection{The Social Planner's Problem}

The social planner (or tax authority) who does not know the true realization of the economic environment, but knows the probability distribution, wants to find an incentive compatible and feasible tax schedule $t^{*}=\left(\left(t_{L,(n-k) L,(k-1) H}^{*}\right)_{k=1}^{n},\left(t_{H,(n-k) L,(k-1) H}^{*}\right)_{k=1}^{n}\right)$ which maximizes the expected sum of agents' utilities. Formally, given $\left(\omega_{L}, \omega_{H}\right) \in \Omega$ and $p \in(0,1)$, the social planner's problem is ${ }^{19}$

$$
\max _{t} W(t ; p)=\mathbb{E}\left[\sum_{i=1}^{n} U_{i}\left(\omega_{i} \mid \omega_{i}, t\right)\right]
$$

subject to

$$
\begin{aligned}
& \text { (IC) } U_{i}\left(\omega_{H} \mid \omega_{H}, t\right) \geqq U_{i}\left(\omega_{L} \mid \omega_{H}, t\right) \quad \forall i \in N, \\
& \text { (Feasibility) } t \in B\left(\omega_{L}, \omega_{H}\right) \equiv\left[0, \omega_{L}\right]^{n} \times\left[0, \omega_{H}\right]^{n} .
\end{aligned}
$$

18 Cancellation of club membership may be an example.

19 Explicitly,

$\left(\mathrm{P}_{n}\right)$

$$
\begin{array}{rl}
\max _{t} & W(t ; p) \\
= & \sum_{j=0}^{n}{ }_{n} C_{j} p^{j}(1-p)^{n-j}\left[n \log \left(j t_{L,(j-1) L,(n-j) H}+(n-j) t_{H,(j-1) L,(n-j) H}\right)\right. \\
& \left.-\left(j t_{L,(j-1) L,(n-j) H}+(n-j) t_{H,(j-1) L,(n-j) H}\right)\right]+n\left(p \omega_{L}+(1-p) \omega_{H}\right)
\end{array}
$$

subject to

$$
\sum_{j=0}^{n-1}{ }_{n-1} C_{j} p^{j}(1-p)^{n-1-j}\left[\operatorname { l o g } \left(j t_{L,(j-1) L,(n-j) H}\right.\right.
$$

$$
\left.\left.+(n-j) t_{H, j L,(n-1-j) H}\right)-t_{H, j L,(n-1-j) H}\right]
$$

$$
\geqq \sum_{j=0}^{n-1}{ }_{n-1} C_{j} p^{j}(1-p)^{n-1-j}\left[\operatorname { l o g } \left((j+1) t_{L, j L,(n-1-j) H}\right.\right.
$$

$$
\left.\left.+(n-1-j) t_{H,(j+1) L,(n-2-j) H}\right)-t_{L, j L,(n-1-j) H}\right],
$$

$\begin{array}{ll}\text { (Feasibility) } & 0 \leqq t_{L,(n-k) L,(k-1) H} \leqq \omega_{L}, \quad \forall k=1, \ldots, n, \\ & 0 \leqq t_{H,(n-k) L,(k-1) H} \leqq \omega_{H}, \quad\end{array}$

where ${ }_{n} C_{j}$ is the number of ways of choosing $j$ unordered outcomes from $n$ possibilities. That is, ${ }_{n} C_{j}=\left(\begin{array}{c}n \\ j\end{array}\right)=\frac{n !}{(n-j) ! j !}$. 
Notice that only one (IC) constraint is binding. For notational simplicity, given $p \in(0,1)$, define a function $\Delta: \mathbb{R}_{+}^{2 n} \rightarrow \overline{\mathbb{R}} \equiv \mathbb{R} \cup\{-\infty,+\infty\}$ by

$$
\Delta(t ; p)=U_{i}\left(\omega_{H} \mid \omega_{H}, t\right)-U_{i}\left(\omega_{L} \mid \omega_{H}, t\right) .
$$

Then, a tax schedule $t$ satisfies (IC) if $\Delta(t ; p) \geqq 0$.

\section{Optimal Feasible Tax Mechanism for $n=2$}

In this section, we study the optimal feasible tax mechanism for the case of two agents. For $n=2$, a tax mechanism $t$ can be written as

$$
t=\left(t_{L L}, t_{L H}, t_{H L}, t_{H H}\right)
$$

where, for example, $t_{L H}$ is the tax payment of an agent when he reports $\omega_{L}$ and the other agent reports $\omega_{H}$. The social planner's problem now becomes: Given $\left(\omega_{L}, \omega_{H}\right) \in \Omega$ and $p \in(0,1)$,

$$
\begin{aligned}
\max _{t} W & W ; p) \\
= & p^{2}\left[2 \log \left(2 t_{L L}\right)-2 t_{L L}\right]+2 p(1-p)\left[2 \log \left(t_{L H}+t_{H L}\right)-\left(t_{L H}+t_{H L}\right)\right] \\
& +(1-p)^{2}\left[2 \log \left(2 t_{H H}\right)-2 t_{H H}\right]+2\left(p \omega_{L}+(1-p) \omega_{H}\right)
\end{aligned}
$$

subject to

$$
\begin{gathered}
(\mathrm{IC})\left[\log \left(t_{L H}+t_{H L}\right)-t_{H L}\right]+(1-p)\left[\log \left(2 t_{H H}\right)-t_{H H}\right] \\
\geqq p\left[\log \left(2 t_{L L}\right)-t_{L L}\right]+(1-p)\left[\log \left(t_{L H}+t_{H L}\right)-t_{L H}\right], \\
0 \leqq t_{L L} \leqq \omega_{L}, \quad 0 \leqq t_{L H} \leqq \omega_{L}, \\
\text { (Feasibility) } 0 \leqq t_{H L} \leqq \omega_{H}, \quad 0 \leqq t_{H H} \leqq \omega_{H} .
\end{gathered}
$$

Note that for $n=2$,

$$
\Delta(t ; p)=p\left[\log \frac{\left(t_{L H}+t_{H L}\right)^{2}}{\left(2 t_{L L}\right)\left(2 t_{H H}\right)}-\left(t_{L H}+t_{H L}\right)+\left(t_{L L}+t_{H H}\right)\right]-\left[\log \frac{t_{L H}+t_{H L}}{2 t_{H H}}+\left(t_{H H}-t_{L H}\right)\right] .
$$

\subsection{Possibility of First Best Taxation}

To begin with, we examine the possibility of the first best tax schedule which is the solution to $\left(\mathrm{P}_{2}\right)$ without $(\mathrm{IC})$ constraint. If the social planner were to know the realization of each agent's endowment, she could easily find the first best tax schedule. However, she does not have such an information, so the question is when the (IC) constraint is not binding. First of all, to rule out the uninteresting cases, partition $\Omega$ (see Figure 1) into

$$
\begin{aligned}
& \Omega_{1}=\left\{\left(\omega_{L}, \omega_{H}\right) \in \Omega: \omega_{L} \in[0,1)\right\}, \text { and } \\
& \Omega_{2}=\left\{\left(\omega_{L}, \omega_{H}\right) \in \Omega: \omega_{L} \in[1, \infty)\right\} .
\end{aligned}
$$

When $\left(\omega_{L}, \omega_{H}\right) \in \Omega_{2}$, the social planner can easily solve $\left(\mathrm{P}_{2}\right)$ by imposing a first best feasible tax schedule

$$
t^{*} \in\left\{t \in B\left(\omega_{L}, \omega_{H}\right): t_{L L}=t_{H H}=1, t_{L H}+t_{H L}=2, \text { and } 1 \leqq t_{L H} \leqq \omega_{L}\right\}
$$


since $t^{*}$ satisfies the (IC) constraint; $\Delta\left(t^{*} ; p\right)=-\left(1-t_{L H}^{*}\right) \geqq 0$. If the social planner insists that the tax schedule be increasing, then the unique solution to $\left(\mathrm{P}_{2}\right)$ is $t^{*}=(1,1,1,1)$. Therefore, in the following we just focus on the case of $\left(\omega_{L}, \omega_{H}\right) \in \Omega_{1}$. According to the welfare function $W(\cdot)$, it is easy to see that for $\left(\omega_{L}, \omega_{H}\right) \in \Omega_{1}$ the first best feasible tax schedule is

$$
t^{F}=\left(t_{L L}^{F}, t_{L H}^{F}, t_{H L}^{F}, t_{H H}^{F}\right)=\left(\omega_{L}, \omega_{L}, \min \left\{\omega_{L}+\omega_{H}, 2\right\}-\omega_{L}, \min \left\{\omega_{H}, 1\right\}\right) .{ }^{20}
$$

To find the conditions under which $t^{F}$ is the solution to $\left(\mathrm{P}_{2}\right)$, consider the (IC) constraint at $t^{F}$ :

$$
\begin{aligned}
\Delta\left(t^{F} ; p\right)= & p\left[\log \frac{\min \left\{\omega_{L}+\omega_{H}, 2\right\}^{2}}{\left(2 \omega_{L}\right)\left(2 \min \left\{\omega_{H}, 1\right\}\right)}-\min \left\{\omega_{L}+\omega_{H}, 2\right\}+\left(\omega_{L}+\min \left\{\omega_{H}, 1\right\}\right)\right] \\
& -\left[\log \frac{\min \left\{\omega_{L}+\omega_{H}, 2\right\}}{2 \min \left\{\omega_{H}, 1\right\}}+\left(\min \left\{\omega_{H}, 1\right\}-\omega_{L}\right)\right] .
\end{aligned}
$$

Lemma 3.1 For $\left(\omega_{L}, \omega_{H}\right) \in \Omega_{1}, \Delta\left(t^{F} ; p\right)$ is strictly increasing in $p$.

Proof: Consider the two cases: (i) $\left(\omega_{L}, \omega_{H}\right) \in[0,1) \times(0,1]$, and (ii) $\left(\omega_{L}, \omega_{H}\right) \in[0,1) \times(1, \infty]$. Case $(\mathrm{i})\left(\omega_{L}, \omega_{H}\right) \in[0,1) \times(0,1]$ : In this case, it is clear that

$$
\frac{\partial \Delta\left(t^{F} ; p\right)}{\partial p}=\log \frac{\left(\omega_{L}+\omega_{H}\right)^{2}}{\left(2 \omega_{L}\right)\left(2 \omega_{H}\right)}>0 .
$$

Case (ii) $\left(\omega_{L}, \omega_{H}\right) \in[0,1) \times(1, \infty]:$ If $\omega_{L}+\omega_{H}<2$,

$$
\frac{\partial \Delta\left(t^{F} ; p\right)}{\partial p}=\log \frac{\left(\omega_{L}+\omega_{H}\right)^{2}}{4 \omega_{L}}-\left(\omega_{H}-1\right)
$$

Since $\frac{\partial}{\partial \omega_{H}}\left(\frac{\partial \Delta\left(t^{F} ; p\right)}{\partial p}\right)=\frac{2}{\omega_{L}+\omega_{H}}-1>0$, it follows that

$$
\frac{\partial \Delta\left(t^{F} ; p\right)}{\partial p}>\lim _{\omega_{H} \rightarrow 1} \frac{\partial \Delta\left(t^{F} ; p\right)}{\partial p}=\log \frac{\left(1+\omega_{L}\right)^{2}}{4 \omega_{L}}>0 .
$$

If $\omega_{L}+\omega_{H} \geqq 2$, then

$$
\frac{\partial \Delta\left(t^{F} ; p\right)}{\partial p}=\omega_{L}-\log \omega_{L}-1>0 .
$$

Therefore, we have the result.

For $\left(\omega_{L}, \omega_{H}\right) \in \Omega_{1}$, define $\bar{\rho} \in \overline{\mathbb{R}}$ by $\Delta\left(t^{F} ; \bar{\rho}\right)=0$, or equivalently,

$$
\bar{\rho}=\frac{\log \frac{\min \left\{\omega_{L}+\omega_{H}, 2\right\}}{2 \min \left\{\omega_{H}, 1\right\}}+\left(\min \left\{\omega_{H}, 1\right\}-\omega_{L}\right)}{\log \frac{\min \left\{\omega_{L}+\omega_{H}, 2\right\}^{2}}{\left(2 \omega_{L}\right)\left(2 \min \left\{\omega_{H}, 1\right\}\right)}-\min \left\{\omega_{L}+\omega_{H}, 2\right\}+\left(\omega_{L}+\min \left\{\omega_{H}, 1\right\}\right)},
$$

and let $\widehat{\rho}=\min \{1, \bar{\rho}\}$. Define also

$$
\Omega^{F}=\left\{\left(\omega_{L}, \omega_{H}\right) \in \Omega_{1}: \lim _{p \rightarrow 0} \Delta\left(t^{F} ; p\right) \geqq 0\right\} .
$$

20 In fact, there is a continuum of first best feasible tax schedules if $\omega_{L}+\omega_{H}>2$. However, given $p, t^{F}$ is the solution to $\left(\mathrm{P}_{2}\right)$ while making (IC) satisfied maximally, so we can assume without loss of generality that $t^{F}$ is the unique first best tax schedule. This point will be made clear in the following. 


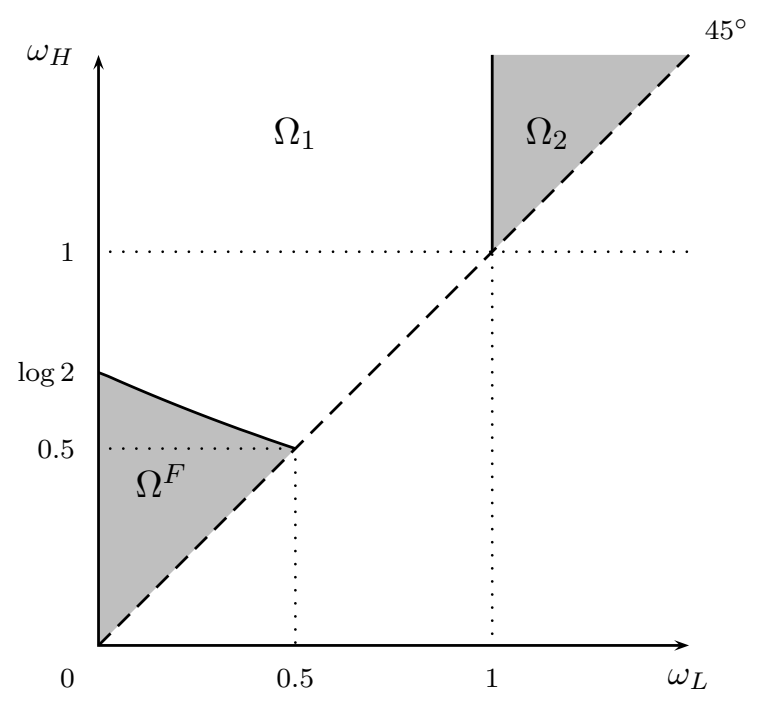

Figure 1: Possibility of First Best Taxation

Proposition 3.2 If $p \geqq \widehat{\rho}$, then the first best feasible tax schedule $t^{F}$ is the unique solution to $\left(P_{2}\right)$. In particular, if $\left(\omega_{L}, \omega_{H}\right) \in \Omega^{F}$, then $t^{F}$ is the unique solution to $\left(P_{2}\right)$ for all $p \in(0,1)$.

Proof: By the definition of $\widehat{\rho}$ and Lemma 3.1, if $p \geqq \widehat{\rho}$, then $\Delta\left(t^{F} ; p\right) \geqq 0$, which implies that $t^{F}$ satisfies (IC). Since $t^{F}$ is feasible, the fact that $t^{F}$ is the unique first best feasible tax schedule proves the first result. It is obvious that $\lim _{p \rightarrow 0} \Delta\left(t^{F} ; p\right) \geqq 0$ guarantees that $\Delta\left(t^{F} ; p\right) \geqq 0$ for all $p \in(0,1)$.

Figure 1 depicts the possibility of first best feasible taxation.

\subsection{Second Best Tax Schedule}

Assume that $p<\hat{\rho}$. To characterize the second best feasible tax schedule, we begin with three lemmas. The main purpose of these lemmas is to lower the dimension of the social planner's problem.

Lemma 3.3 Suppose $t^{*}$ is a solution to $\left(P_{2}\right)$. Then,

$$
t_{H H}^{*}=\min \left\{\omega_{H}, 1\right\} .
$$

Proof: There are two cases: (i) $\omega_{H} \leqq 1$, and (ii) $\omega_{H}>1$.

Case (i) $\omega_{H} \leqq 1$ : Suppose by way of contradiction that $t_{H H}^{*}<\omega_{H}$. Choose $\varepsilon$ such that $0<\varepsilon \leqq$ $\omega_{H}-t_{H H}^{*}$. Consider a new tax schedule $t^{\prime}=\left(t_{L L}^{*}, t_{L H}^{*}, t_{H L}^{*}, t_{H H}^{*}+\varepsilon\right)$. Since $\log \left(2 t_{H H}\right)-t_{H H}$ is strictly increasing in $t_{H H} \in(0,1)$, it follows that

$$
U_{i}\left(\omega_{H} \mid \omega_{H}, t^{\prime}\right)>U_{i}\left(\omega_{H} \mid \omega_{H}, t^{*}\right) \geqq U_{i}\left(\omega_{L} \mid \omega_{H}, t^{*}\right)=U_{i}\left(\omega_{L} \mid \omega_{H}, t^{\prime}\right) .
$$

Hence, $t^{\prime}$ satisfies (IC). Also, $t^{\prime}$ satisfies (Feasibility) by the construction of $\varepsilon$. However, we have $W\left(t^{\prime} ; p\right)>W\left(t^{*} ; p\right)$, a contradiction to the hypothesis that $t^{*}$ is a solution.

Case (ii) $\omega_{H}>1$ : Suppose by way of contradiction that $t_{H H}^{*} \neq 1$. If $t_{H H}^{*}<1$, choose $\varepsilon$ such that $0<\varepsilon \leqq 1-t_{H H}^{*}$. Then the same argument in Case (i) induces a contradiction. If $t_{H H}^{*}>1$, choose 
$\varepsilon$ such that $0<\varepsilon \leqq t_{H H}^{*}-1$, and consider a new tax schedule $t^{\prime}=\left(t_{L L}^{*}, t_{L H}^{*}, t_{H L}^{*}, t_{H H}^{*}-\varepsilon\right)$. Then, the same argument in Case (i) also gives a contradiction.

Lemma 3.4 Suppose $t^{*}$ is a solution to $\left(P_{2}\right)$. Then,

$$
t_{L H}^{*}+t_{H L}^{*} \leqq 2 .
$$

Proof: Suppose by way of contradiction that $t_{L H}^{*}+t_{H L}^{*}>2$. Note that this case is possible only when $\omega_{L}+\omega_{H}>2$. Choose $\varepsilon$ such that $0<\log \left(t_{L H}^{*}+t_{H L}^{*}\right)-\log \left(t_{L H}^{*}+t_{H L}^{*}-\varepsilon\right)<\frac{\varepsilon}{2}$. Such an $\varepsilon$ is well defined since $\frac{d}{d y}(\log y)<\frac{1}{2}$ for $y>2$. Consider a new tax schedule $t^{\prime}=\left(t_{L L}^{*}, t_{L H}^{*}, t_{H L}^{*}-\varepsilon, t_{H H}^{*}\right)$. Then,

$$
\begin{aligned}
U_{i}\left(\omega_{H} \mid \omega_{H}, t^{\prime}\right) & =p\left[\log \left(t_{L H}^{*}+t_{H L}^{*}-\varepsilon\right)-t_{H L}^{*}+\varepsilon\right]+(1-p)\left[\log \left(2 t_{H H}^{*}\right)-t_{H H}^{*}\right] \\
& >p\left[\log \left(t_{L H}^{*}+t_{H L}^{*}\right)-t_{H L}^{*}+\frac{\varepsilon}{2}\right]+(1-p)\left[\log \left(2 t_{H H}^{*}\right)-t_{H H}^{*}\right] \\
& >p\left[\log \left(t_{L H}^{*}+t_{H L}^{*}\right)-t_{H L}^{*}\right]+(1-p)\left[\log \left(2 t_{H H}^{*}\right)-t_{H H}^{*}\right] \\
& \geqq p\left[\log \left(2 t_{L L}^{*}\right)-t_{L L}^{*}\right]+(1-p)\left[\log \left(t_{L H}^{*}+t_{H L}^{*}\right)-t_{L H}^{*}\right] \\
& >p\left[\log \left(2 t_{L L}^{*}\right)-t_{L L}^{*}\right]+(1-p)\left[\log \left(t_{L H}^{*}+t_{H L}^{*}-\varepsilon\right)-t_{L H}^{*}\right] \\
& =U_{i}\left(\omega_{L} \mid \omega_{H}, t^{\prime}\right)
\end{aligned}
$$

which implies that $t^{\prime}$ satisfies (IC). Also, $t^{\prime}$ satisfies (Feasibility) by construction. However, since

$$
\begin{aligned}
2 \log \left(t_{L H}^{\prime}+t_{H L}^{\prime}\right)-\left(t_{L H}^{\prime}+t_{H L}^{\prime}\right) & =2 \log \left(t_{L H}^{*}+t_{H L}^{*}-\varepsilon\right)-\left(t_{L H}^{*}+t_{H L}^{*}-\varepsilon\right) \\
& >2 \log \left(t_{L H}^{*}+t_{H L}^{*}\right)-\left(t_{L H}^{*}+t_{H L}^{*}\right),
\end{aligned}
$$

we have $W\left(t^{\prime} ; p\right)>W\left(t^{*} ; p\right)$, a contradiction to the hypothesis that $t^{*}$ is a solution.

Lemma 3.5 Suppose $t^{*}$ is a solution to $\left(P_{2}\right)$. Then,

$$
t_{L H}^{*}=\omega_{L}, \quad \text { and } \quad t_{H L}^{*} \geqq \omega_{L} .
$$

Proof: If $\omega_{L}=0$, then the claim is trivial. Hence, consider the case of $\omega_{L}>0$. Suppose by way of contradiction that (i) $t_{H L}^{*}<\omega_{L}$; or (ii) $t_{L H}^{*}<\omega_{L}$ and $t_{H L}^{*} \geqq \omega_{L}$.

Case (i) $t_{H L}^{*}<\omega_{L}$ : Consider a new tax schedule $t^{\prime}=\left(\omega_{L}, \omega_{L}, \omega_{L}, \min \left\{\omega_{H}, 1\right\}\right)$. Then,

$$
\Delta\left(t^{\prime} ; p\right)=-(1-p)\left[\log \frac{\omega_{L}}{\min \left\{\omega_{H}, 1\right\}}-\omega_{L}+\min \left\{\omega_{H}, 1\right\}\right]>0
$$

which implies that $t^{\prime}$ satisfies (IC). Also, $t^{\prime}$ satisfies (Feasibility). However, we have $W\left(t^{\prime} ; p\right)>$ $W\left(t^{*} ; p\right)$, a contradiction to the hypothesis that $t^{*}$ is a solution.

Case (ii) $t_{L H}^{*}<\omega_{L}$ and $t_{H L}^{*} \geqq \omega_{L}$ : According to Lemma 3.4, we have two subcases: (a) $t_{L H}^{*}+t_{H L}^{*}<$ 2 ; or (b) $t_{L H}^{*}+t_{H L}^{*}=2$.

Subcase (a) $t_{L H}^{*}+t_{H L}^{*}<2$ : Choose $\varepsilon$ such that $0<\varepsilon \leqq \min \left\{\omega_{L}-t_{L H}^{*}, 2-\left(t_{L H}^{*}+t_{H L}^{*}\right)\right\}$. Consider a new tax schedule $t^{\prime}=\left(t_{L L}^{*}, t_{L H}^{*}+\varepsilon, t_{H L}^{*}-\varepsilon, t_{H H}^{*}\right)$. Then,

$$
\begin{aligned}
U_{i}\left(\omega_{H} \mid \omega_{H}, t^{\prime}\right) & =U_{i}\left(\omega_{H} \mid \omega_{H}, t^{*}\right)+p \varepsilon \\
& >U_{i}\left(\omega_{L} \mid \omega_{H}, t^{*}\right) \\
& =U_{i}\left(\omega_{L} \mid \omega_{H}, t^{\prime}\right)+(1-p) \varepsilon \\
& >U_{i}\left(\omega_{L} \mid \omega_{H}, t^{\prime}\right),
\end{aligned}
$$


which implies that $\Delta\left(t^{\prime} ; p\right)>0$, that is, the (IC) constraint is not tightly binding. Since $\Delta(t ; p)$ is continuous in $t_{H L}$, we can choose $\delta \in(0, \varepsilon)$ such that $t^{\prime \prime}=t^{\prime}+(0,0, \delta, 0)$ still satisfies (IC) and (Feasibility). Notice that $t_{L H}^{*}+t_{H L}^{*}=t_{L H}^{\prime}+t_{H L}^{\prime}<t_{L H}^{\prime \prime}+t_{H L}^{\prime \prime}<2$, and $t_{L L}^{\prime \prime}=t_{L L}^{*}$, and $t_{H H}^{\prime \prime}=t_{H H}^{*}$. Hence, we have $W\left(t^{\prime \prime} ; p\right)>W\left(t^{*} ; p\right)$, a contradiction to the hypothesis that $t^{*}$ is a solution.

Subcase (b) $t_{L H}^{*}+t_{H L}^{*}=2$ : Notice that in this case $\omega_{H}>1$ since $t_{H L}^{*}=2-t_{L H}^{*}>2-\omega_{L}>1$. First, we want to show that $t_{L L}^{*}<\omega_{L}$. Suppose not, that is, $t_{L L}^{*}=\omega_{L}$. Since $t_{H H}^{*}=1$ by Lemma 3.3, it turns out that

$$
\Delta\left(t^{*} ; p\right)=p\left(\omega_{L}-\log \omega_{L}-1\right)-\left(1-\omega_{L}\right)<0,
$$

since $p<\widehat{\rho}=\frac{1-\omega_{L}}{\omega_{L}-\log \omega_{L}-1}$. This is a contradiction to the hypothesis that $t^{*}$ satisfies (IC). So, $t_{L L}^{*}<\omega_{L}$.

Consider a new tax schedule $t^{\prime}=\left(t_{L L}^{*}, t_{L H}^{*}+\varepsilon, t_{H L}^{*}-\varepsilon, t_{H H}^{*}\right)$ where $\varepsilon$ is chosen such that $0<\varepsilon \leqq \omega_{L}-t_{L H}^{*}$. Then, by (3), we have $\Delta\left(t^{\prime} ; p\right)>0$, that is, the (IC) constraint is not tightly binding. Since $\Delta(t ; p)$ is continuous in $t_{L L}$ and $t_{L L}^{*}<\omega_{L}$, we can choose $\delta \in\left(0, \omega_{L}-t_{L L}^{*}\right)$ such that $t^{\prime \prime}=t^{\prime}+(\delta, 0,0,0)$ still satisfies (IC) and (Feasibility). Since $2 \log \left(2 t_{L L}^{\prime \prime}\right)-2 t_{L L}^{\prime \prime}>2 \log \left(2 t_{L L}^{*}\right)-2 t_{L L}^{*}$, we have $W\left(t^{\prime \prime} ; p\right)>W\left(t^{*} ; p\right)$, a contradiction to the hypothesis that $t^{*}$ is a solution.

Therefore, we conclude that $t_{L H}^{*}=\omega_{L}$ and $t_{H L}^{*} \geqq \omega_{L}$.

By Lemmas 3.3-3.5, we can reduce the dimension of $\left(\mathrm{P}_{2}\right)$ from four to two. Let $T=t_{L H}+t_{H L}$. Lemmas 3.3-3.5 implies that we can restrict our attention to $\left(T, t_{L L}\right) \in\left[2 \omega_{L}, \min \left\{\omega_{L}+\omega_{H}, 2\right\}\right] \times$ $\left[0, \omega_{L}\right]$, which now can be called a tax schedule. Define $(I C)$-function $z(\cdot, \cdot ; p):\left[2 \omega_{L}, \min \left\{\omega_{L}+\right.\right.$ $\left.\left.\omega_{H}, 2\right\}\right] \times\left[0, \omega_{L}\right] \rightarrow \overline{\mathbb{R}}$, by

$$
\begin{aligned}
z\left(T, t_{L L} ; p\right)= & \left.\Delta\left(t_{L L}, t_{L H}, t_{H L}, t_{H H} ; p\right)\right|_{t_{L H}=\omega_{L}, t_{H H}=\min \left\{\omega_{H}, 1\right\}} \\
= & p\left[\log \frac{T^{2}}{\left(2 t_{L L}\right)\left(2 \min \left\{\omega_{H}, 1\right\}\right)}-T+\left(t_{L L}+\min \left\{\omega_{H}, 1\right\}\right)\right] \\
& -\left[\log \frac{T}{2 \min \left\{\omega_{H}, 1\right\}}+\left(\min \left\{\omega_{H}, 1\right\}-\omega_{L}\right)\right] .
\end{aligned}
$$

Thus, a tax schedule $\left(T, t_{L L}\right)$ satisfies (IC) if $z\left(T, t_{L L} ; p\right) \geqq 0$.

Now, the social planner's problem $\left(\mathrm{P}_{2}\right)$ can be written as an equivalent but simplified version $\left(\mathrm{P}_{2}^{\prime}\right)$ : Given $\left(\omega_{L}, \omega_{H}\right) \in \Omega_{1}$ and $p \in(0,1)$,

$$
\begin{aligned}
\max _{\left(T, t_{L L}\right)} & \widetilde{W}\left(T, t_{L L} ; p\right) \\
& =p^{2}\left[2 \log \left(2 t_{L L}\right)-2 t_{L L}\right]+2 p(1-p)[2 \log T-T]
\end{aligned}
$$

subject to

$$
\text { (IC) } \quad z\left(T, t_{L L} ; p\right) \geqq 0
$$

$$
\text { (Feasibility) } \quad\left(T, t_{L L}\right) \in\left[2 \omega_{L}, \min \left\{\omega_{L}+\omega_{H}, 2\right\}\right] \times\left[0, \omega_{L}\right] .
$$

To find the second best tax schedule, first consider the shape of the $(I C)$-curve $z\left(T, t_{L L} ; p\right)=0$. In fact, we can find a point that satisfies $z\left(T, t_{L L} ; p\right)=0$ for all $p \in(0,1)$. For $\left(\omega_{L}, \omega_{H}\right) \in \Omega \backslash \Omega_{F}$, let

$$
\begin{aligned}
\widetilde{T} & =2 \min \left\{\omega_{H}, 1\right\} e^{-\left(\min \left\{\omega_{H}, 1\right\}-\omega_{L}\right)}, \text { and } \\
\widetilde{t}_{L L} & =-W_{0}\left(-\exp \left\{\log \frac{\widetilde{T}}{2}-\widetilde{T}+\omega_{L}\right\}\right),
\end{aligned}
$$


where $W_{0}$ is the principal branch of Lambert $W$ function. ${ }^{21}$ By the definition of $\widetilde{T}$, we can rewrite the (IC)-curve as

$$
z\left(T, t_{L L} ; p\right)=p\left[\log \frac{T^{2}}{\left(2 t_{L L}\right)(\widetilde{T})}-T+\left(t_{L L}+\omega_{L}\right)\right]-\left[\log \frac{T}{\widetilde{T}}\right],
$$

so, it is clear that $z\left(\widetilde{T}, \widetilde{t}_{L L} ; p\right)=0$ for all $p \in(0, \widehat{\rho})$. That is, the (IC)-curve $z\left(T, t_{L L} ; p\right)=0$ always goes through the pivotal point $\left(\widetilde{T}, \widetilde{t}_{L L}\right)$. Furthermore,

Lemma 3.6 i. $\left(\widetilde{T}, \widetilde{t}_{L L}\right) \in\left(2 \omega_{L}, \min \left\{\omega_{L}+\omega_{H}, 2\right\}\right) \times[0,1)$.

ii. If $\widetilde{T} \leqq 1$, then $\widetilde{t}_{L L}>\omega_{L}$.

Proof: i. Since $\log \left(\min \left\{\omega_{H}, 1\right\}\right)-\min \left\{\omega_{H}, 1\right\}>\log \left(\omega_{L}\right)-\omega_{L}$, it is clear that $\widetilde{T}>2 \omega_{L}$. For $\left(\omega_{L}, \omega_{H}\right) \in \Omega_{1} \backslash \Omega^{F}, \log \frac{\min \left\{\omega_{L}+\omega_{H}, 2\right\}}{2 \min \left\{\omega_{H}, 1\right\}}+\left(\min \left\{\omega_{H}, 1\right\}-\omega_{L}\right)=-\lim _{p \rightarrow 0} \Delta\left(t^{F} ; p\right)>0$, so $\widetilde{T}<$ $\min \left\{\omega_{L}+\omega_{H}, 2\right\}$. To see that $\widetilde{t}_{L L} \in[0,1)$, by Lambert $W$ function, it suffices to show that $\varphi\left(\omega_{L}, \omega_{H}\right) \equiv \log \frac{\widetilde{T}}{2}-\widetilde{T}+\omega_{L}<-1$. Note that since $\widetilde{T}>2 \omega_{L}$,

$$
\begin{aligned}
\varphi\left(\omega_{L}, \omega_{H}\right) & =\log \left(\min \left\{\omega_{H}, 1\right\}\right)-\min \left\{\omega_{H}, 1\right\}-\widetilde{T}+2 \omega_{L} \\
& <\log \left(\min \left\{\omega_{H}, 1\right\}\right)-\min \left\{\omega_{H}, 1\right\} \\
& \leqq-1
\end{aligned}
$$

ii. Since $0 \leqq \widetilde{t}_{L L}<1$, the result is equivalent to $\widetilde{t}_{L L}-\log \widetilde{t}_{L L} \leqq \omega_{L}-\log \omega_{L}$, or $\log \frac{\widetilde{T}}{2 \omega_{L}}-\widetilde{T}+2 \omega_{L} \geqq 0$. By $2 \omega_{L}<\widetilde{T} \leqq 1$, we have the result.

This lemma tells that if $\widetilde{T} \leqq 1$, the pivotal point $\left(\widetilde{T}, \widetilde{t}_{L L}\right)$ is above the feasible set $\left[2 \omega_{L}, \min \left\{\omega_{L}+\right.\right.$ $\left.\left.\omega_{H}, 2\right\}\right] \times\left[0, \omega_{L}\right]$. Another property of the (IC)-curve is that it turns around the pivotal point $\left(\widetilde{T}, \widetilde{t}_{L L}\right)$ counterclockwise as $p$ increases.

Lemma 3.7 For all $p, p^{\prime} \in(0,1)$ such that $p<p^{\prime}$, if $z\left(T, t_{L L} ; p\right)=0$, then

$$
z\left(T, t_{L L} ; p^{\prime}\right)=\left\{\begin{array}{ll}
<0 & \text { if } T<\widetilde{T} \\
\geqq 0 & \text { if } T \geqq \widetilde{T}
\end{array} .\right.
$$

Proof: Since

$$
z\left(T, t_{L L} ; p^{\prime}\right)=\left(\frac{p^{\prime}}{p}\right) z\left(T, t_{L L} ; p\right)+\left(\frac{p^{\prime}}{p}-1\right)\left[\log \frac{T}{\widetilde{T}}\right]=\left(\frac{p^{\prime}}{p}-1\right)\left[\log \frac{T}{\widetilde{T}}\right]
$$

we have the result easily.

Figure 2 depicts the subsets of $\Omega$ that satisfy $\widetilde{t}_{L L} \geqq \omega_{L}$ and $\widetilde{T}>1$.

21 The Lambert $W$ function is defined to be the function satisfying $W(x) e^{W(x)}=x$. This function is defined on $\left[-e^{-1}, \infty\right)$, and has a single real value on $[0, \infty)$ and two real values on $\left[-e^{-1}, 0\right)$. $W_{0}$, called the principal branch, is the increasing part of $W$ and $W_{-1}$, called the $(-1)$ th branch, is the decreasing part of $W$. The solution of the equation $x b^{x}=a$ is $x=\frac{1}{\log b} W(a \log b)$. For more properties on the Lambert $W$ function, see Corless, et. al. [1996]. (We reluctantly employ the notational abuse, $W$, previously used for the welfare function. Hopefully, it may not cause any confusion in the following.) 


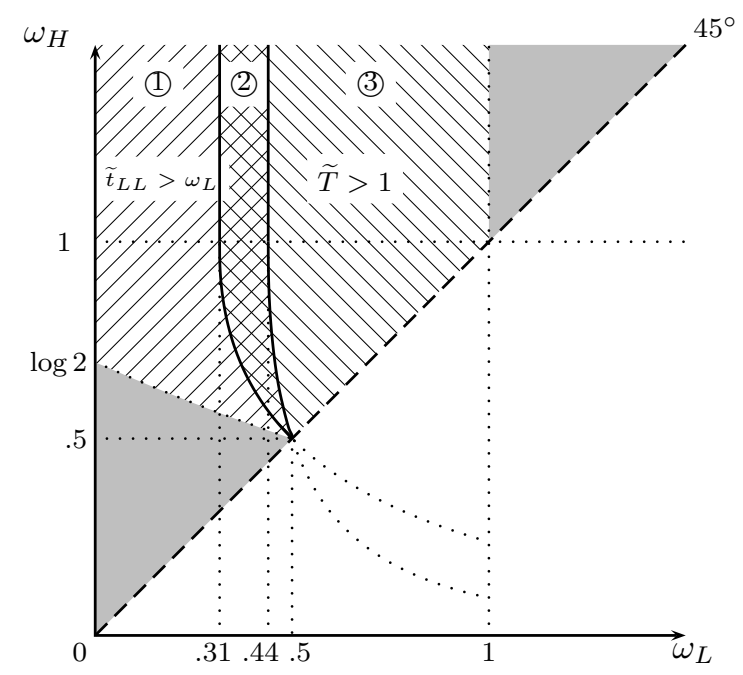

Figure 2: Relative size of $\left(\widetilde{T}, \widetilde{t}_{L L}\right)$ on $\Omega$

Now, consider the slope of $(I C)$-curve $z\left(T, t_{L L} ; p\right)=0$. Without loss of generality, we can restrict our attention to the domain of $[0,2] \times[0,1)$, which includes all of the possible $\left(T, t_{L L}\right) .{ }^{22}$ Using the Implicit Function Theorem,

$$
\left.\frac{d t_{L L}}{d T}\right|_{z\left(T, t_{L L} ; p\right)=0}=-\left.\frac{\frac{2 p-1}{T}-p}{p\left(1-\frac{1}{t_{L L}}\right)}\right|_{z\left(T, t_{L L} ; p\right)=0} .
$$

Since we restrict $t_{L L}$ on $[0,1)$, the denominator is negative. If $p \leqq \frac{1}{2}$, then the numerator is negative for all $T \in[0,2]$. If $p \in\left(\frac{1}{2}, 1\right)$, then the numerator is positive for $T \in\left(0, \frac{2 p-1}{p}\right)$ and negative for $T \in\left(\frac{2 p-1}{p}, 2\right)$. As a result, for $\left(T, t_{L L}\right) \in[0,2] \times[0,1)$,

$$
\left.\frac{d t_{L L}}{d T}\right|_{z\left(T, t_{L L} ; p\right)=0} \begin{cases}>0 & \text { if } p \in\left(\frac{1}{2}, 1\right) \text { and } T \in\left(0, \frac{2 p-1}{p}\right) \\ =0 & \text { if } p \in\left(\frac{1}{2}, 1\right) \text { and } T=\frac{2 p-1}{p} \\ <0 & \text { otherwise }\end{cases}
$$

Remark 3.8 According to the inequality (2), it turns out that for $\left(\omega_{L}, \omega_{H}\right) \in \Omega_{1}$, the curve defined by $z\left(T, t_{L L} ; p\right)=0$ on $\left(T, t_{L L}\right) \in\left[2 \omega_{L}, \min \left\{\omega_{L}+\omega_{H}, 2\right\}\right] \times\left[0, \omega_{L}\right]$ has a negative slope because the point $\left(T, t_{L L}\right)$ that has zero slope cannot be in $\left[2 \omega_{L}, \min \left\{\omega_{L}+\omega_{H}, 2\right\}\right] \times\left[0, \omega_{L}\right]$.

The slope of welfare-curve $\widetilde{W}\left(T, t_{L L} ; p\right)=\bar{w}$, where $\bar{w}$ is a constant, is

$$
\left.\frac{d t_{L L}}{d T}\right|_{\widetilde{W}\left(T, t_{L L} ; p\right)=\bar{w}}=-\left.\frac{p(1-p)\left(\frac{2}{T}-1\right)}{p^{2}\left(\frac{1}{t_{L L}}-1\right)}\right|_{\widetilde{W}\left(T, t_{L L} ; p\right)=\bar{w}}<0
$$

$\overline{22}$ Note that $z\left(T, t_{L L} ; p\right)=0$ defines multiple curves on $\mathbb{R}^{2}$ while it defines a single curve on $[0,2] \times[0,1)$. 
for $\left(T, t_{L L}\right) \in[0,2] \times[0,1)$. That is, the welfare-curve $\widetilde{W}\left(T, t_{L L} ; p\right)=\bar{w}$ has a negative slope on $[0,2] \times[0,1)$.

To describe the second best feasible tax schedule, we need some definitions. First, for $\left(\omega_{L}, \omega_{H}\right) \in$ $\Omega_{1}$ such that $\omega_{L}+\omega_{H} \leqq 1$ and $p \in(0, \widehat{\rho})$, define $\underline{t}_{L L} \in\left(0, \omega_{L}\right)$ by $z\left(\omega_{L}+\omega_{H}, 2, \underline{t}_{L L} ; p\right)=0$. Second, for $p \in(0, \hat{\rho})$, define $\underline{T} \in\left(2 \omega_{L}, \min \left\{\omega_{L}+\omega_{H}, 2\right\}\right)$ by $z\left(\underline{T}, \omega_{L} ; p\right)=0$. Third, define simply $T^{o}=1$. Finally, for $\widetilde{T}<1$ and $\underline{T}<1$, define $t_{L L}^{o} \in\left(0, \omega_{L}\right)$ by $z\left(1, t_{L L}^{o} ; p\right)=0 .{ }^{23}$

Now, we can state the main result of this paper.

Proposition 3.9 For $p<\widehat{\rho}$, the solution to $\left(P_{2}\right)$ is

$$
t^{*}=\left\{\begin{array}{ll}
\left(\underline{t}_{L L}, \omega_{L}, \omega_{H}, \omega_{H}\right) & \text { if } \omega_{L}+\omega_{H} \leqq T^{o} \\
\left(t_{L L}^{o}, \omega_{L}, T^{o}-\omega_{L}, \min \left\{\omega_{H}, 1\right\}\right) & \text { if } \underline{T} \leqq T^{o} \\
\left(\omega_{L}, \omega_{L}, \underline{T}-\omega_{L}, \min \left\{\omega_{H}, 1\right\}\right) & \text { if } \underline{T}>T^{o}
\end{array} .\right.
$$

Proof: Notice from (4) and (5) that the (IC)-curve $z\left(T, t_{L L} ; p\right)=0$ is tangent to the welfare-curve $\widetilde{W}\left(T, t_{L L} ; p\right)=\bar{w}$ at $\left(T, t_{L L}\right)=\left(T^{o}, t_{L L}^{o}\right)$.

For the interior solution (the third case), we need to show that the tangent point $\left(T^{o}, t_{L L}^{o}\right)$ is maximizing the welfare function $\widetilde{W}(\cdot)$ rather than minimizing. This can be done by showing that

$$
\left.\frac{d^{2} t_{L L}}{d T^{2}}\right|_{\widetilde{W}\left(T^{o}, t_{L L}^{o} ; p\right)=\bar{w}}>\left.\frac{d^{2} t_{L L}}{d T^{2}}\right|_{z\left(T^{o}, t_{L L}^{o} ; p\right)=0} .
$$

Differentiating (4) and (5), it follows that

$$
\begin{aligned}
\left.\frac{d^{2} t_{L L}}{d T^{2}}\right|_{\widetilde{W}\left(T^{o}, t_{L L}^{o} ; p\right)=\bar{w}}-\left.\frac{d^{2} t_{L L}}{d T^{2}}\right|_{z\left(T^{o}, t_{L L}^{o} ; p\right)=0} & =\left.\frac{1}{p T\left(1-t_{L L}\right)}\left[\frac{t_{L L}}{T}-\left(\frac{1-T}{1-t_{L L}}\right) \frac{d t_{L L}}{d T}\right]\right|_{T=T^{o}, t_{L L}=t_{L L}^{o}} \\
& =\frac{t_{L L}^{o}}{p\left(1-t_{L L}^{o}\right)} \\
& >0 .
\end{aligned}
$$

For the corner solutions (the firs and second cases), we need to show that

$$
\left.\left.T \lessgtr 1 \Longrightarrow \frac{d t_{L L}}{d T}\right|_{\widetilde{W}\left(T, t_{L L} ; p\right)=\bar{w}} \lessgtr \frac{d t_{L L}}{d T}\right|_{z\left(T, t_{L L} ; p\right)=0},
$$

respectively. From (4) and (5), we have

$$
\left.\frac{d t_{L L}}{d T}\right|_{\widetilde{W}\left(T, t_{L L} ; p\right)=\bar{w}}-\left.\frac{d t_{L L}}{d T}\right|_{z\left(T, t_{L L} ; p\right)=0}=\frac{1}{p^{2}}\left(\frac{t_{L L}}{1-t_{L L}}\right)\left(\frac{T-1}{T}\right) \lessgtr 0 \quad \text { for } T \lessgtr 1,
$$

respectively, since $t_{L L} \in[0,1)$. Therefore, we have $t^{*}$ as stated.

Table 1 summarize the optimal feasible tax schedules and their relative size for each possible case.

${ }_{23}$ Using Lambert $W$ function, we can express $\underline{t}_{L L}, \underline{T}$, and $t_{L L}^{o}$ explicitly as

$$
\begin{aligned}
\underline{t}_{L L} & =-W_{0}\left(-\exp \left\{\log \frac{\left(\omega_{L}+\omega_{H}\right)^{2}}{2 \widetilde{T}}-\omega_{H}-\left(\frac{1}{p}\right) \log \frac{\omega_{L}+\omega_{H}}{\widetilde{T}}\right\}\right) ; \\
\underline{T} & =-\left(\frac{2 p-1}{p}\right) W\left(-\left(\frac{p}{2 p-1}\right) \exp \left\{\left(\frac{p}{2 p-1}\right)\left[\log \left(\left(2 \omega_{L}\right)(\widetilde{T})\right)-2 \omega_{L}\right]-\left(\frac{1}{2 p-1}\right) \log (\widetilde{T})\right\}\right) ; \\
t_{L L}^{o} & =-W_{0}\left(-\exp \left\{\log \frac{1}{2 \widetilde{T}}-1+\omega_{L}-\left(\frac{1}{p}\right) \log \frac{1}{\widetilde{T}}\right\}\right) .
\end{aligned}
$$

For $\underline{T}, W$ should be $W_{-1}$ if $p>\frac{1}{2}$ and $W_{0}$ if $p \leqq \frac{1}{2}$. 


\begin{tabular}{|c|c|c|c|c|c|c|c|c|c|}
\hline \multicolumn{3}{|l|}{ Cases } & $t_{L L}^{*}$ & & $t_{L H}^{*}$ & & $t_{H L}^{*}$ & & $t_{H H}^{*}$ \\
\hline \multicolumn{3}{|c|}{$p \geqq \widehat{\rho}\left(\right.$ including $\left.\Omega^{F}\right)$} & & & $\omega_{L}$ & $<$ & $\min \left\{\omega_{L}+\omega_{H}, 2\right\}-\omega_{L}$ & $\geqq$ & $\min \left\{\omega_{H}, 1\right\}$ \\
\hline \multirow[t]{3}{*}{$p<\widehat{\rho}$} & \multicolumn{2}{|l|}{$\omega_{L}+\omega_{H} \leqq 1$} & $\underline{t}_{L L}$ & $\leqq$ & $\omega_{L}$ & $<$ & $\omega_{H}$ & $=$ & $\omega_{H}$ \\
\hline & \multirow[t]{2}{*}{$\omega_{L}+\omega_{H}>1$} & $\underline{T} \leqq 1$ & $t_{L L}^{o}$ & $\leqq$ & $\omega_{L}$ & $<$ & $T^{o}-\omega_{L}$ & $<$ & $\min \left\{\omega_{H}, 1\right\}$ \\
\hline & & $\underline{T}>1$ & $\omega_{L}$ & $=$ & $\omega_{L}$ & $<$ & $\underline{T}-\omega_{L}$ & $\lesseqgtr$ & $\min \left\{\omega_{H}, 1\right\}$ \\
\hline
\end{tabular}

Table 1: Optimal feasible tax schedules for $n=2$.

\subsection{Simulated Examples}

In this section, we illustrate some examples that show the specific optimal feasible tax schedules for different parameter values. Due to the low dimensionality of the social planner's problem, we can draw the results graphically.

\section{Example 3.10}

i. Suppose first that $\left(\omega_{L}, \omega_{H}\right)=(0.2,0.5)$. In this case, $\widehat{\rho} \approx-0.28$, so $p \geqq \hat{\rho}$ for all $p \in(0,1)$. In particular, this is the example of $\left(\omega_{L}, \omega_{H}\right) \in \Omega^{F}$. Thus, the first best feasible tax schedule $\left(t_{L L}^{*}, t_{L H}^{*}, t_{H L}^{*}, t_{H H}^{*}\right)=(0.2,0.2,0.5,0.5)$ is obtained.

ii. Suppose that $\left(\omega_{L}, \omega_{H}\right)=(0.1,0.8)$. In this case, $\widehat{\rho} \approx 0.13$.

(a) If $p \geqq \widehat{\rho}$, the first best tax schedule $\left(t_{L L}^{*}, t_{L H}^{*}, t_{H L}^{*}, t_{H H}^{*}\right)=(0.1,0.1,0.8,0.8)$ is obtained. Figure 3(a) illustrates the case of $p=0.3$.

(b) If $p<\widehat{\rho}$, by Proposition 3.9, the second best tax schedule $t^{*}=\left(\underline{t}_{L L}, \omega_{L}, \omega_{H}, \omega_{H}\right)$ is obtained. Figure 3(b) illustrates the case of $p=0.1$ in which the optimal tax schedule is $\left(t_{L L}^{*}, t_{L H}^{*}, t_{H L}^{*}, t_{H H}^{*}\right)=$ $(0.07,0.1,0.8,0.8)$.

iii. Suppose that $\left(\omega_{L}, \omega_{H}\right)=(0.25,0.8)$. In this case, $\widehat{\rho} \approx 0.4$.

(c) If $p=0.35$ as illustrated in Figure $3(\mathrm{c})$, then $\underline{T} \approx 1.02>1$, so the second best tax schedule $t^{*}=\left(\omega_{L}, \omega_{L}, \underline{T}-\omega_{L}, \omega_{H}\right)=(0.25,0.25,0.77,0.8)$ is obtained.

(d) If $p=0.2$ illustrated in Figure $3(\mathrm{~d})$, then $\underline{T} \approx 0.97<1$, so the second best tax schedule $t^{*}=\left(t_{L L}^{o}, \omega_{L}, T^{o}-\omega_{L}, \omega_{H}\right)=(0.21,0.25,0.75,0.8)$ is obtained.

iv. Figure $3(\mathrm{e})-(\mathrm{h})$ show some other cases that have the second best tax schedule for different parameter values.

\section{Properties and Comparative Statics}

\subsection{Properties of Optimal Feasible Tax Schedules}

First, consider the possibility of first best feasible taxation. For a first best feasible tax schedule to be a solution to the social planner's problem, it should not give any incentive for an agent to misreport his endowment. Since the incentive compatibility constraint is unilateral in our model, 


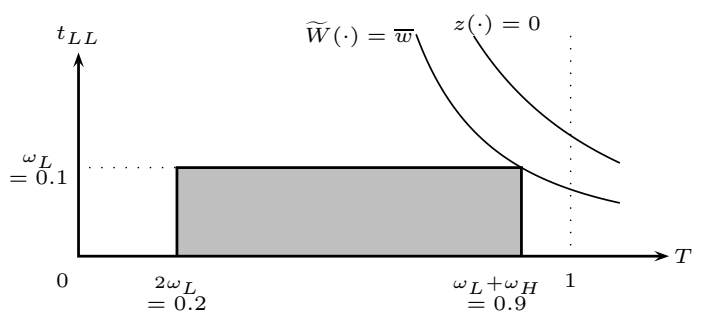

(a) $\left(\omega_{L}, \omega_{H}\right)=(0.1,0.8), p=0.3$

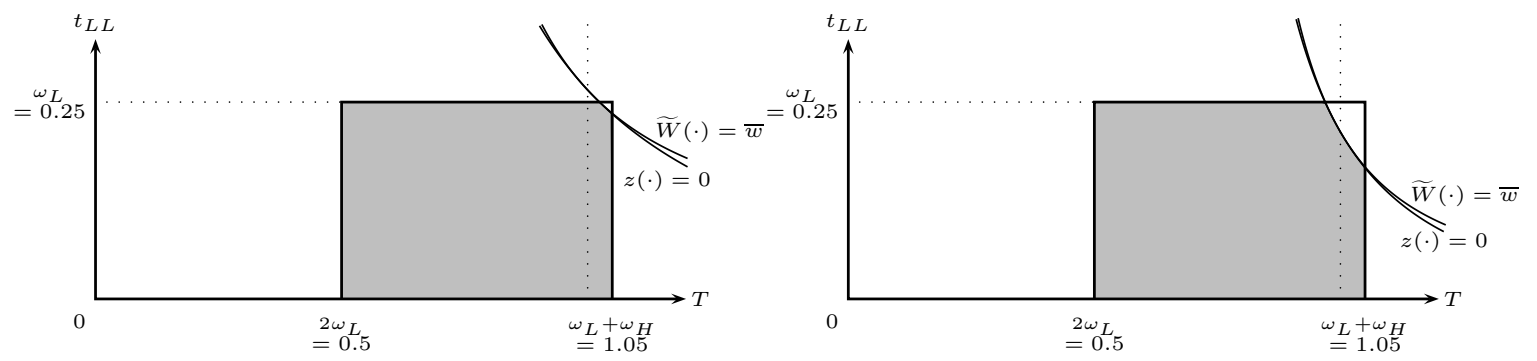

(c) $\left(\omega_{L}, \omega_{H}\right)=(0.25,0.8), p=0.35$

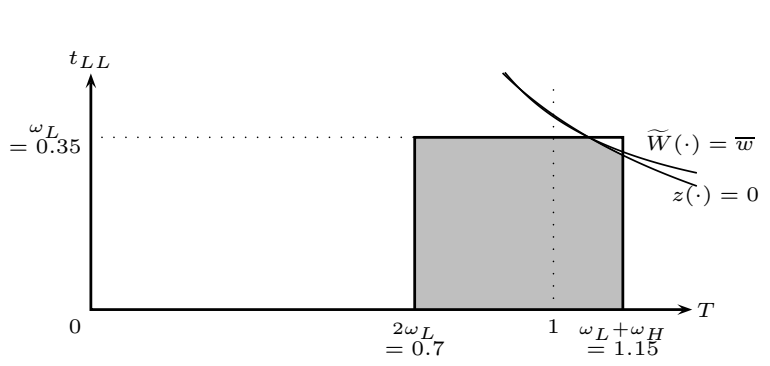

(e) $\left(\omega_{L}, \omega_{H}\right)=(0.35,0.8), p=0.5$

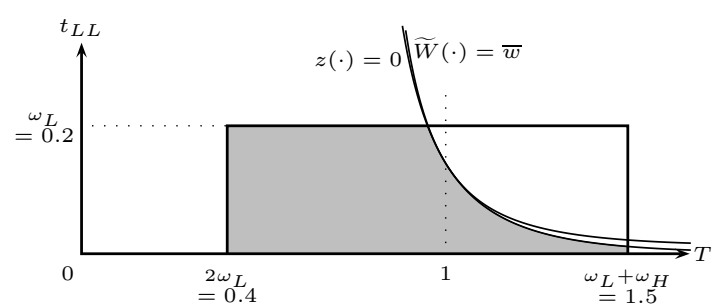

(g) $\left(\omega_{L}, \omega_{H}\right)=(0.2,1.3), p=0.15$

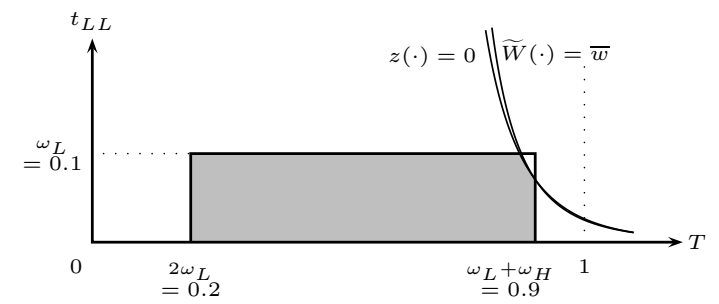

(b) $\left(\omega_{L}, \omega_{H}\right)=(0.1,0.8), p=0.1$

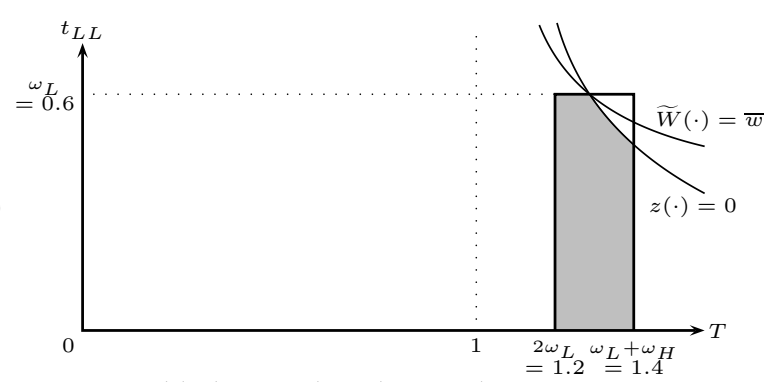

(f) $\left(\omega_{L}, \omega_{H}\right)=(0.6,0.8), p=0.5$

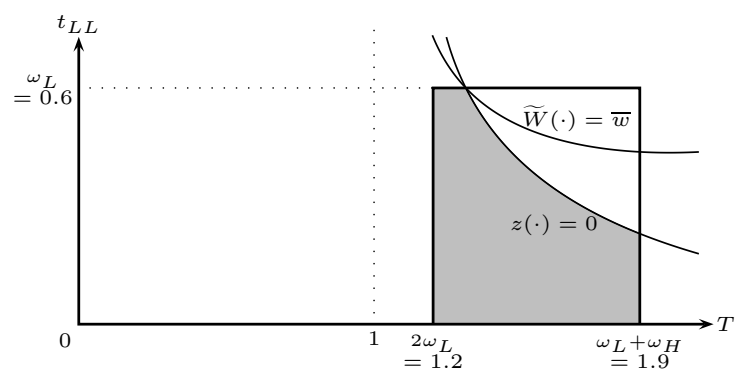

(h) $\left(\omega_{L}, \omega_{H}\right)=(0.6,1.3), p=0.5$

Figure 3: An example of second best taxation 
this requirement says that a rich agent should have no incentive to lie. According to the characterization results in the previous section, when (i) $p \geqq \widehat{\rho}$, or (ii) $\left(\omega_{L}, \omega_{H}\right) \in \Omega_{2}$, the corresponding first best feasible tax schedules can be a solution to the social planner's problem $\left(\mathrm{P}_{2}\right)$. For the case of (ii), the endowment of a poor agent is large enough that the first best feasible tax schedule could impose the same amount of tax on each agent for any case. ${ }^{24}$ Thus, a rich agent has no incentive to misreport his type. On the other hand, for the case of (i), since the overall endowment level of the economy is small enough (the case of $\Omega^{F}$ ) or the probability of low endowment is high enough, a rich agent worries mainly about that too low amount of public good would be provided if he misreports. Thus, he will not lie. Therefore, when the total endowment of the economy is relatively low enough or high enough, first best feasible taxation satisfies the incentive compatibility constraint so that it can be the solution to $\left(\mathrm{P}_{2}\right)$.

Second, the optimal feasible tax schedule always imposes $100 \%$ tax rate on a poor agent when his neighbor is rich. ${ }^{25}$ That is, $t_{L H}^{*}=\omega_{L}$ for all $\left(\omega_{L}, \omega_{H}\right) \in \Omega_{1}$ and all $p \in(0,1)$. This result reflects the effect of informational rent on the economy which pursues efficiency rather than equity as its objective. Due to the no exaggeration assumption, the incentive compatibility constraint in this model is unilateral so that levying a tax on a poor agent does not create any incentive problem as long as it is feasible. Thus, the social planner, who does not mind which agent pays how much proportion of the total taxes, prefers to impose as much tax as possible on the poor agent rather than his rich neighbor who may request informational rent. Of course, the absolute amount of tax payment of rich agent is strictly higher than that of poor agent. However, since there do exist some cases in which the tax rate imposed on the rich agent is strictly less than $100 \%$, we can say that the optimal feasible tax mechanism is regressive.

Third, the optimal feasible tax schedule is increasing.

Proposition 4.1 For all $\left(\omega_{L}, \omega_{H}\right) \in \Omega_{1}$,

$$
t_{L L}^{*} \leqq t_{H L}^{*} \quad \text { and } \quad t_{L H}^{*} \leqq t_{H H}^{*} .
$$

Proof: The first inequality is clear since Lemma 3.5 implies that $t_{L L}^{*} \leqq \omega_{L} \leqq t_{H L}^{*}$. The second inequality is also clear since $t_{L H}^{*}=\omega_{L}<\min \left\{\omega_{H}, 1\right\}$.

Thus, under the optimal feasible tax mechanism each agent's tax payment is increasing with his endowment. Note, however, that this increasingness does not imply that marginal tax rate is increasing.

Finally, we note the property that for all $\left(\omega_{L}, \omega_{H}\right) \in \Omega, t_{L L}^{*} \leqq t_{L H}^{*}$ with strict inequality for some cases as can be seen in Table 1. That is, a poor agent may say, "If my neighbor is rich, then I have to pay more!" This can be interpreted in a quite similar way used in the second property above; a poor agent should take some extra burden caused by his rich neighbor, which would not have been incurred had his neighbor been poor. In Rhee [2004b], we tackle this problem in detail by comparing the immigration incentives of an agent to the communities with different expected endowments.

24 Note that it is assumed that an increasing tax schedule is used on $\Omega_{2}$.

25 As mentioned in Section 2.1, each agent's initial endowment is considered as his taxable wealth. Thus, the $100 \%$ tax rate is acceptable in this sense. 


\subsection{Comparative Statics}

One of the interesting questions about the optimal feasible tax schedule is how the optimal feasible tax schedule $t^{*}$ will respond to the change in the probability of low endowment $p$. We are also interested in how $t^{*}$ will change as $\omega_{L}$ or $\omega_{H}$ varies. In the following, we exclude the trivial case $\Omega_{2}$ in which first best taxation is always possible.

\subsubsection{Responses of $t^{*}$ to $p$}

Since both $t_{L H}^{*}$ and $t_{H H}^{*}$ are independent of $p$, it suffices to analyze the responses of $t_{L L}^{*}$ and $t_{H L}^{*}$. Given $\left(\omega_{L}, \omega_{H}\right) \in \Omega_{1}$, if $p \geqq \widehat{\rho}$, then $t^{*}$ is independent of $p$. Thus, suppose $p<\widehat{\rho}$. By Lemma 3.7, we have the following subcases.

(1) $\omega_{L}+\omega_{H} \leqq 1$

In this case, only $t_{L L}^{*}=\underline{t}_{L L}$ depends on $p$. Since the principal branch $W_{0}$ of the Lambert $W$ function is strictly increasing, it follows that $\frac{d \underline{t}_{L L}}{d p}>0$, that is, $t_{L L}^{*}$ is strictly increasing.

(2) $\omega_{L}+\omega_{H}>1$

Case (i) $\widetilde{t}_{L L} \geqq \omega_{L}$ : If $\underline{T} \leqq 1$, then only $t_{L L}^{*}=t_{L L}^{o}$ depends on $p$. By the definition of $t_{L L}^{o}$, it turns out that

$$
\left.\frac{d t_{L L}}{d p}\right|_{z\left(T^{o}, t_{L L}^{o} ; p\right)=0}=-\left.\frac{\left(\frac{1}{p}\right) \log \frac{T}{\widetilde{T}}}{p\left(1-\frac{1}{t_{L L}}\right)}\right|_{z\left(T^{o}, t_{L L}^{o} ; p\right)=0}>0
$$

since the nominator is negative by $t_{L L}^{o}<1$ and the denominator is negative by $\widetilde{T}<\underline{T} \leqq 1=T^{o}$. Hence, $t_{L L}^{*}$ is strictly increasing. If $\underline{T}>1$, then only $t_{H L}^{*}=\underline{T}-\omega_{L}$ depends on $p$. Since $\widetilde{T} \leqq \underline{T}$ and $\underline{T}>\frac{2 p-1}{p}$ by Remark 3.8 , it follows that

$$
\left.\frac{d T}{d p}\right|_{z\left(\underline{T}, \omega_{L} ; p\right)=0}=-\left.\frac{\left(\frac{1}{p}\right) \log \frac{T}{\widetilde{T}}}{\frac{2 p-1}{T}-p}\right|_{z\left(\underline{T}, \omega_{L} ; p\right)=0} \geqq 0
$$

which implies that $t_{H L}^{*}$ is increasing. ${ }^{26}$

Case (ii) $\widetilde{t}_{L L}<\omega_{L}$ : In this case, we claim that $1<\underline{T} \leqq \widetilde{T}$. By Remark $3.8, \underline{T} \leqq \widetilde{T}$ is clear. To see that $1<\underline{T}$, note that

$$
z\left(1, \omega_{L} ; p\right)=p\left[\log \frac{1}{\left(2 \omega_{L}\right)(\widetilde{T})}-1+2 \omega_{L}\right]+\log \widetilde{T}=p\left[\log \frac{1}{2 \omega_{L}}-1+2 \omega_{L}\right]+(1-p) \log \widetilde{T}>0 .
$$

That is, the (IC)-curve is always above the point $\left(1, \omega_{L}\right)$, which implies $1<\underline{T}$. Thus, only $t_{H L}^{*}=$ $\underline{T}-\omega_{L}$ depends on $p$. By $(6), \frac{d \underline{T}}{d p}<0$, so $t_{H L}^{*}$ is strictly decreasing.

\section{(3) Interpretation}

Table 2 summarizes the responses of $t^{*}$ to $p$ for each possible case. Figure 4 shows the examples for some different endowments values. ${ }^{27}$ Roughly speaking, $t_{L L}^{*}$ is (weakly) increasing for $p$ increases.

26 The equality holds only if $\widetilde{t}_{L L}=\omega_{L}$.

27 In Figure $4, \beta \in(0,1)$ is defined such that $z\left(1, \omega_{L} ; \beta\right)=0$. 


\begin{tabular}{l|l|l||ccccc}
\hline \hline \multicolumn{2}{l|}{ Cases } & $\frac{d t_{L L}^{*}}{d p}$ & $\frac{d t_{L H}^{*}}{d p}$ & $\frac{d t_{H L}^{*}}{d p}$ & $\frac{d t_{H H}^{*}}{d p}$ \\
\hline \hline$p \geqq \hat{\rho}\left(\right.$ including $\left.\Omega^{F}\right)$ & & 0 & 0 & 0 & 0 \\
\hline$p<\hat{\rho}$ & $\omega_{L}+\omega_{H} \leqq 1$ & & + & 0 & 0 & 0 \\
\cline { 2 - 7 } & \multirow{2}{*}{$\omega_{L}+\omega_{H}>1$} & \multirow{2}{*}{$\tilde{t}_{L L} \geqq \omega_{L}$} & $\underline{T} \leqq 1$ & + & 0 & 0 & 0 \\
\cline { 3 - 8 } & & $\underline{T}>1$ & 0 & 0 & + & 0 \\
\cline { 3 - 8 } & & $\tilde{t}_{L L}<\omega_{L}$ & & 0 & 0 & - & 0 \\
\hline \hline
\end{tabular}

Table 2: A summary of the responses of $t^{*}$ to $p$.

However, $t_{H L}^{*}$ is (weakly) increasing for relatively low $\omega_{L}$, but decreasing for large $\omega_{L}$. In fact, these results show how the (IC) constraint will change as the probability of low endowment $p$ increases.

Suppose first that the initial low endowment is small enough such that $\widetilde{t}_{L L} \geqq \omega_{L}$ (the areas of (1) and (2) in Figure 2). In this case, the increase in $p$ makes the (IC) constraint less tight for both $t_{L L}^{*}$ and $t_{H L}^{*}$ in the sense that the set of incentive compatible and feasible tax schedules becomes larger. ${ }^{28}$ Thus, the social planner can increase $t_{L L}^{*}$ or $t_{H L}^{*}$ as long as the feasibility constraint is binding. That is, for $\underline{T} \leqq 1$ (the interior solution case), $t_{L L}^{*}$ increases but $t_{H L}^{*}$ stays the same since the solution always occurs at $T^{o}=1$, and for $\underline{T}>1$ (the corner solution case), $t_{H L}^{*}$ increases but $t_{L L}^{*}$ is fixed at its feasible maximum $\omega_{L}$. The economic intuition behind this result is as follows: The social planner has to take into account the informational rent incurred by a rich agent. When $\omega_{L}$ is relatively small such that $\widetilde{t}_{L L} \geqq \omega_{L}$, the social planner can design an incentive compatible tax mechanism without much worrying about such an informational rent because the rich agent is reluctant to lie to avoid too small provision of public good. Thus, as $p$ increases, the rich agent (IC) constraint becomes less tight. (Figure 4(a)(b)(e)(f)).

On the other hand, suppose that the initial low endowment $\omega_{L}$ is relatively large such that $\widetilde{t}_{L L}<\omega_{L}$ (the area of (3) in Figure 2). ${ }^{29}$ In this case, the increase in $p$ makes the (IC) constraint less tight for $t_{L L}^{*}$ but tighter for $t_{H L}^{*}$ in the sense that the set of incentive compatible and feasible tax schedules becomes larger with respect to $t_{L L}^{*}$, but smaller with respect to $t_{H L}^{*}$. Thus, the social planner would like to decrease $t_{H L}^{*}$ and increase $t_{L L}^{*}$ as long as the feasibility constraint is binding. Since in this case $t_{L L}^{*}$ is already set at its maximum $\omega_{L}$ (the corner solution case), only $t_{H L}^{*}$ should be decreased. This result can be interpreted as follows: If $\omega_{L}$ is relatively large, then too small public good provision is no longer a big problem. Thus, as $p$ increases, the rich agent is more willing to lie, which implies that the social planner should decrease the rich agent's tax payment thl* to make him honest (Figure $4(\mathrm{c})(\mathrm{d})(\mathrm{g})(\mathrm{h}))$.

$28 \quad$ Recall by Lemma 3.7 that the (IC)-curve $z\left(T, t_{L L} ; p\right)=0$ turns counterclockwise around the pivotal point $\left(\widetilde{T}, \widetilde{t}_{L L}\right)$ as $p$ increases.

29 Note that in this case, $\widetilde{T}>1$ by Lemma 3.6 . 


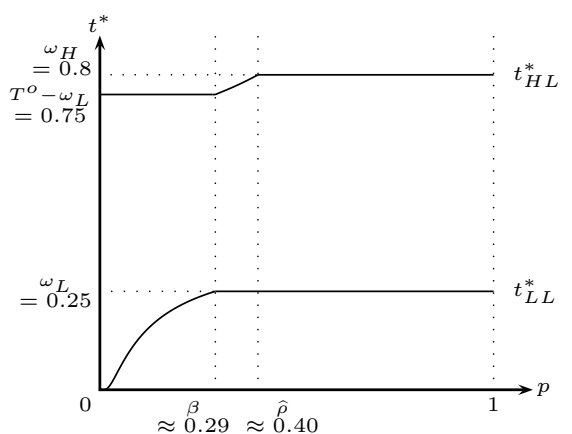

(a) $\left(\omega_{L}, \omega_{H}\right)=(0.25,0.8)$

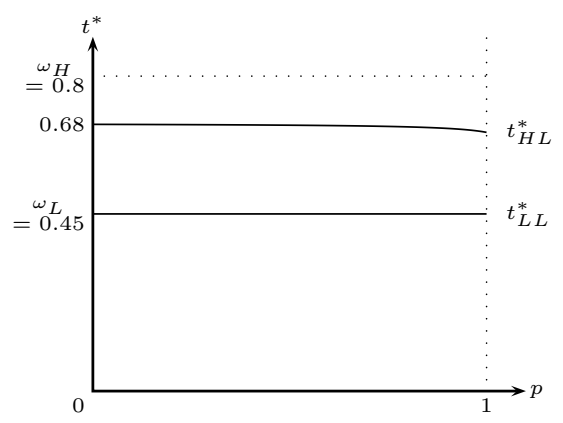

(c) $\left(\omega_{L}, \omega_{H}\right)=(0.45,0.8)$

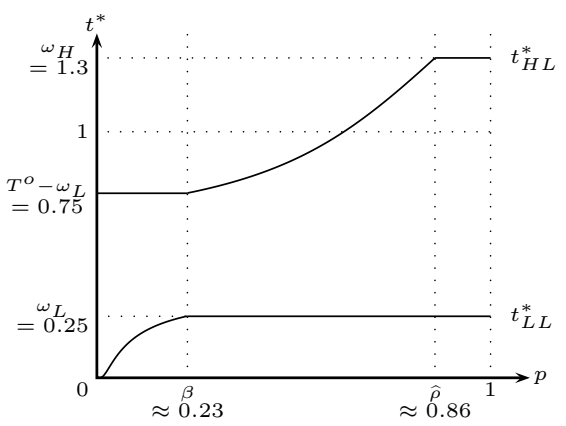

(e) $\left(\omega_{L}, \omega_{H}\right)=(0.25,1.3)$

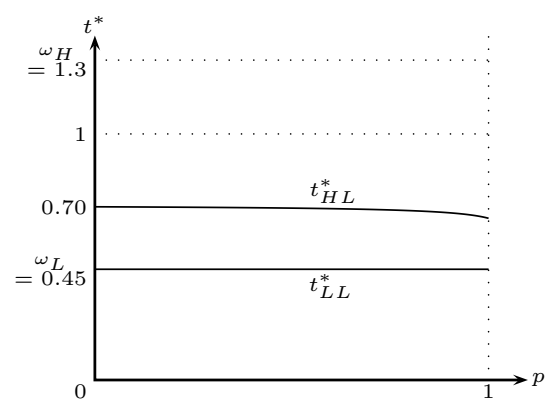

(g) $\left(\omega_{L}, \omega_{H}\right)=(0.45,1.3)$

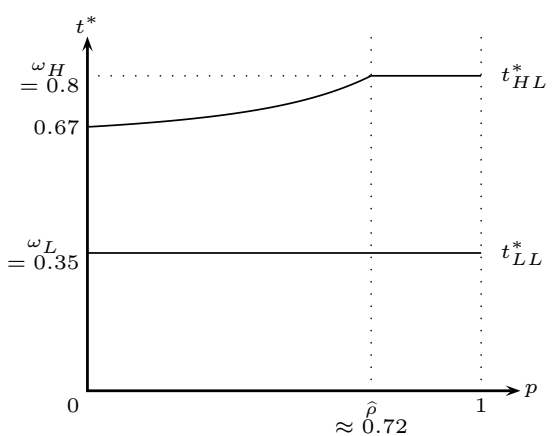

(b) $\left(\omega_{L}, \omega_{H}\right)=(0.35,0.8)$

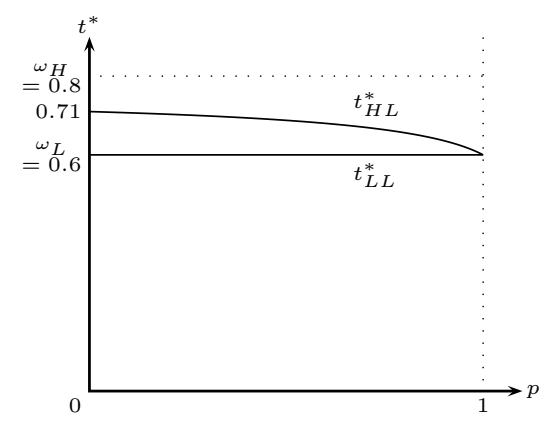

(d) $\left(\omega_{L}, \omega_{H}\right)=(0.6,0.8)$



(f) $\left(\omega_{L}, \omega_{H}\right)=(0.35,1.3)$



(h) $\left(\omega_{L}, \omega_{H}\right)=(0.6,1.3)$

Figure 4: Responses of $t_{L L}^{*}$ and $t_{H L}^{*}$ to $p$ 


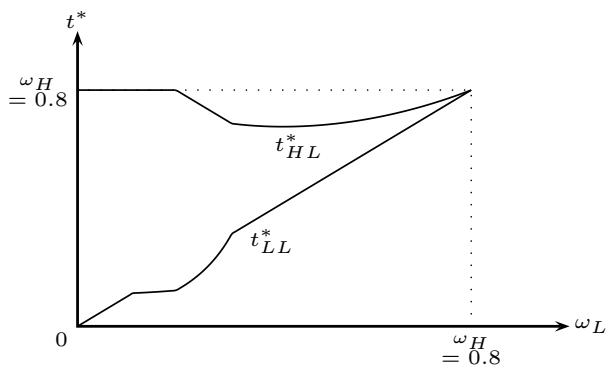

(a) $\omega_{H}=0.8, p=0.15$

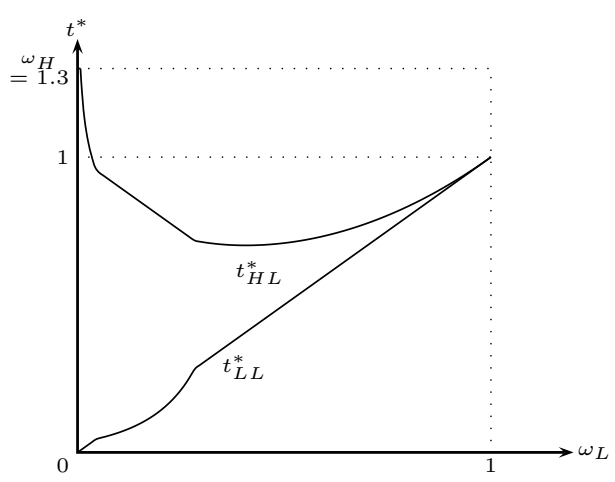

(c) $\omega_{H}=1.3, p=0.15$

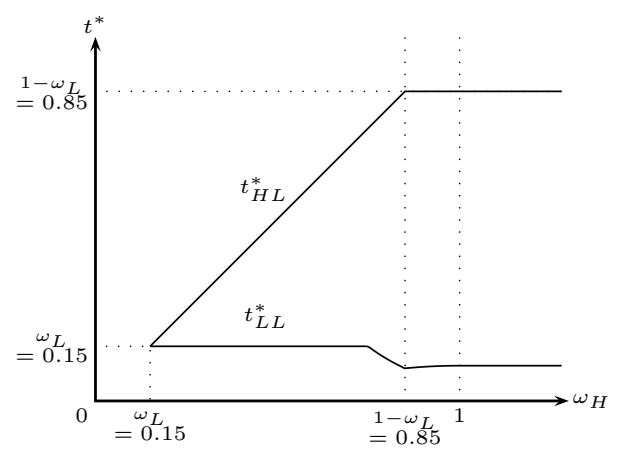

(e) $\omega_{L}=0.15, p=0.15$

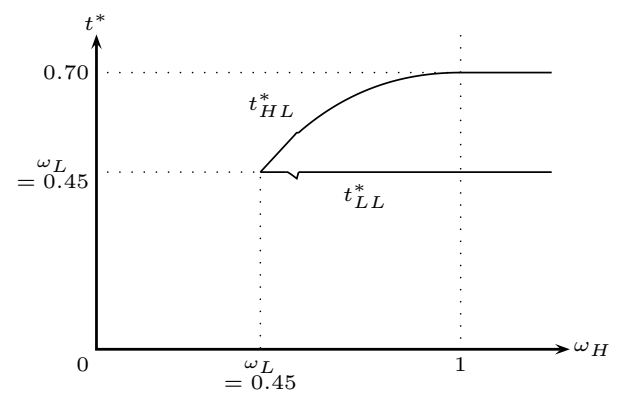

(g) $\omega_{L}=0.45, p=0.15$

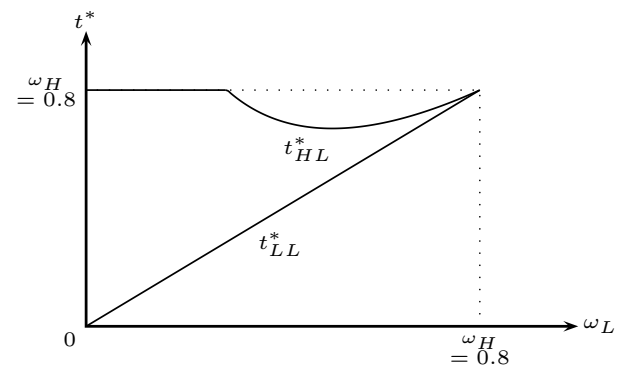

(b) $\omega_{H}=0.8, p=0.5$

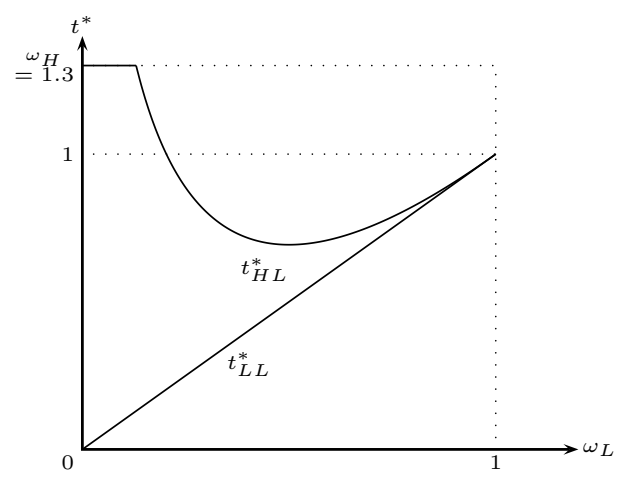

(d) $\omega_{H}=1.3, p=0.5$

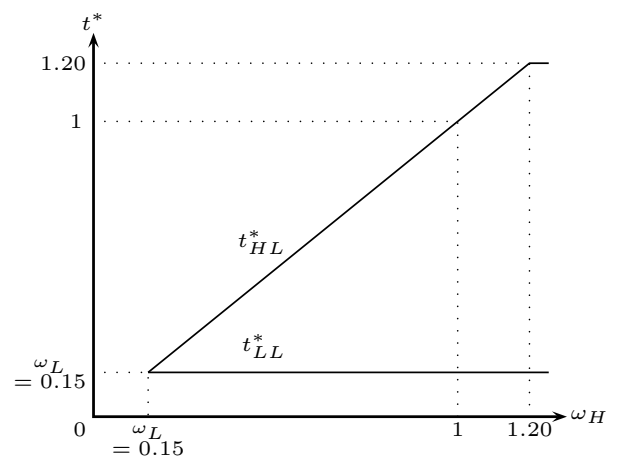

(f) $\omega_{L}=0.15, p=0.5$

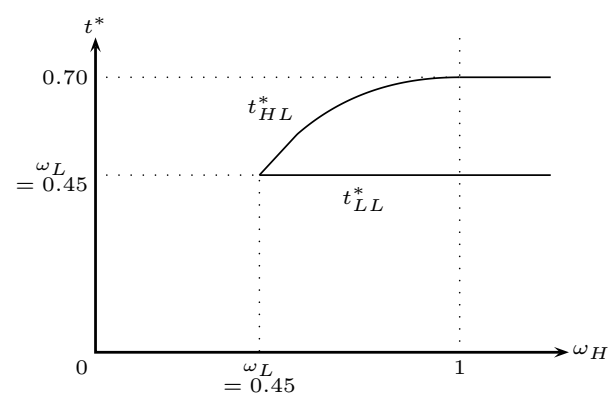

(h) $\omega_{L}=0.45, p=0.5$

Figure 5: Responses of $t_{L L}^{*}$ and $t_{H L}^{*}$ to $\omega_{L}$ and $\omega_{H}$ 


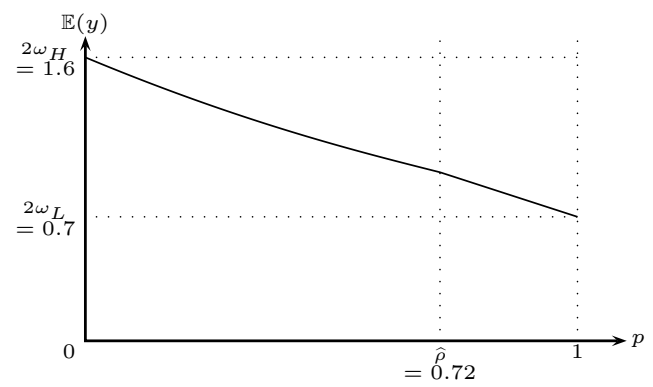

(a) $\left(\omega_{L}, \omega_{H}\right)=(0.35,0.8)$

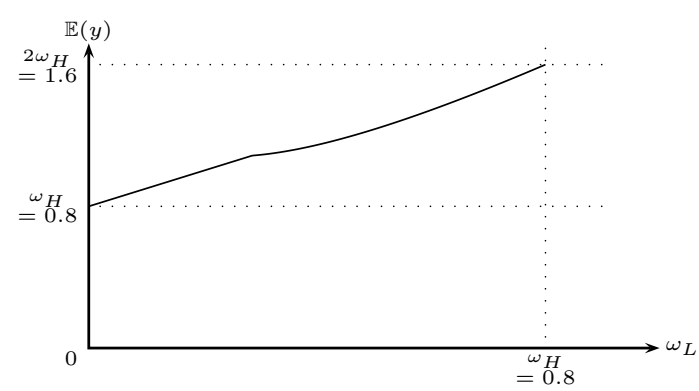

(c) $\omega_{H}=0.8, p=0.5$

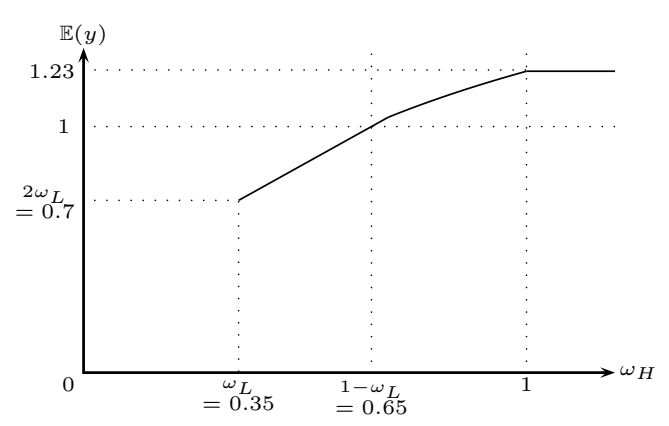

(e) $\omega_{L}=0.35, p=0.5$

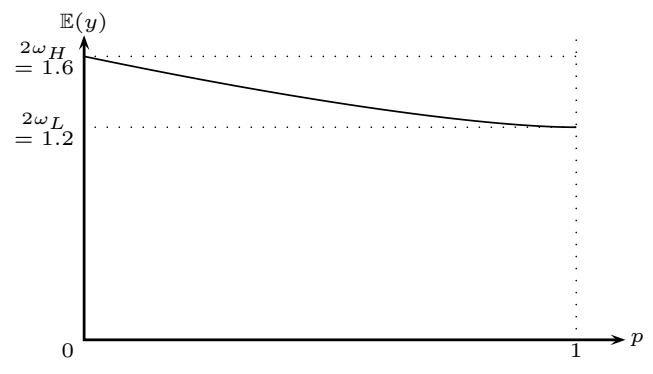

(b) $\left(\omega_{L}, \omega_{H}\right)=(0.6,0.8)$

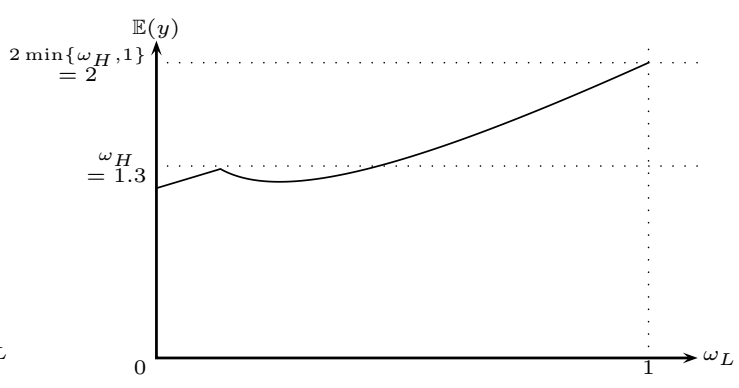

(d) $\omega_{H}=1.3, p=0.5$



(f) $\omega_{L}=0.6, p=0.5$

Figure 6: Expected Total Provision of Public Good: $\mathbb{E}(y)$

\subsubsection{Responses of $t^{*}$ to $\omega_{L}$ or $\omega_{H}$}

We have already studied rough responses of $t^{*}$ to $\omega_{L}$ or $\omega_{H}$ by its characterization for different cases on $\Omega$. Now, we provide some simulated examples for better understanding the optimal feasible tax mechanism. Figure 5(a)-(d) show the responses of $t^{*}$ to $\omega_{L}$ and Figure 5(e)-(h) to $\omega_{H}$ when $p=0.15$ or 0.5 .

Consider first the responses to a change in $\omega_{L}$. As $\omega_{L}$ increases, we can see that $t_{L L}^{*}$ is increasing, but $t_{H L}^{*}$ is (weakly) decreasing for lower values of $\omega_{L}$ and then increasing for larger values. These results can be interpreted as follows. For lower $\omega_{L}$, a first best solution like Figure 3(a) is possible so that $t_{L L}^{*}$ and $t_{H L}^{*}$ are set their maximum. As $\omega_{L}$ increases more, a corner solution like Figure 3(b) could occur depending on the values of $\omega_{H}$ and $p$. In this case, $t_{H L}^{*}$ stays the same at its maximal but $t_{L L}$ would be less than $\omega_{L}$. As $\omega_{L}$ increases furthermore, then an interior solution like Figure 3(d) will happen. In this case, $t_{L L}^{*}$ will increase but $t_{H L}^{*}$ will decrease. As $\omega_{L}$ increases even further, a corner solution like Figure $3(\mathrm{e})$ or $(\mathrm{f})$ is obtained. In this case, $t_{H L}^{*}$ is decreasing initially and then 
increasing, and $t_{L L}^{*}$ is increasing with $\omega_{L}$. One of the interesting implications from these results is that an increase in $\omega_{L}$ can decrease the tax burden of a rich agent if $\omega_{L}$ is relatively small.

We can apply a similar interpretation to the change of $\omega_{H}$. That is, for lower $\omega_{H}$, a first best solution like Figure 3(a) is obtained, and then a corner solution like Figure 3(b) and/or an interior solution like Figure 3(d) is obtained depending on the values of $\omega_{L}$ and $p$. Eventually, the optimal solution ends up an interior one like Figure 3(d) or a corner solution like Figure 3(e) or (f). Notice also that an increase in $\omega_{H}$ can decrease the tax burden of a poor agent if $\omega_{L}$ is relatively small and $\omega_{H}$ is relatively large (see Figure $3(\mathrm{e})$ ).

\subsubsection{Expected Total Provision of Public Good}

Finally, we show how much public goods will be provided as $p, \omega_{L}$, or $\omega_{H}$ varies. The expected total provision of public good is expressed as

$$
\mathbb{E}(y)=p^{2}\left(2 t_{L L}^{*}\right)+2 p(1-p)\left(t_{L H}^{*}+t_{H L}^{*}\right)+(1-p)^{*}\left(2 t_{H H}^{*}\right) .
$$

The Figure 6 illustrates some examples of those responses. Roughly speaking, $\mathbb{E}(y)$ increases as $\omega_{L}$ or $\omega_{H}$ increase, and as $p$ decreases. ${ }^{30}$ In particular, for large $\omega_{H}$, the increase in $\omega_{L}$ may reduce $\mathbb{E}(y)$ (Figure $6(\mathrm{~d})$ ). This fact reflects the observation that the increase of $\omega_{L}$ may decrease $t_{H L}^{*}$ so much. Thus, even if $t_{L L}^{*}$ and $t_{L H}^{*}$ increase with $\omega_{L}$, the decrease of $t_{H L}^{*}$ is still dominating, which results in the smaller $\mathbb{E}(y)$.

\section{Optimal Feasible Tax Mechanism for $n>2$}

As the extension of the case $n=2$, we now study the optimal feasible tax schedule for $2<n<\infty$, $t^{*}=\left(\left(t_{L,(n-k) L,(k-1) H}^{*}\right)_{k=1}^{n},\left(t_{H,(n-k) L,(k-1) H}^{*}\right)_{k=1}^{n}\right)$, which is the solution to $\left(\mathrm{P}_{n}\right)$. To begin with, consider the case of $\left(\omega_{L}, \omega_{H}\right) \in \Omega_{2}$. The social planner can easily solve $\left(\mathrm{P}_{n}\right)$ by imposing a first best feasible tax schedule

$$
\begin{aligned}
t^{*} \in\{ & t \in\left[0, \omega_{L}\right]^{n} \times\left[0, \omega_{H}\right]^{n}: t_{L,(n-1) L, 0 H}=1, t_{H, 0 L,(n-1) H}=1 ; \\
& (n-k) t_{L,(n-1-k) L, k H}+k t_{H,(n-k) L,(k-1) H}=n, \text { and } \\
& \left.1 \leqq t_{L,(n-1-k) L, k H} \leqq \omega_{L}, \text { for } k=1, \ldots, n-1\right\} .
\end{aligned}
$$

since $t^{*}$ satisfies the (IC) constraint; ${ }^{31}$

$$
\Delta\left(t^{F} ; p\right)=\sum_{j=1}^{n-1}{ }_{n-1} C_{j-1} p^{j-1}(1-p)^{n-1-j}\left(t_{L,(j-1) L,(n-j) H}^{F}-1\right) \geqq 0 .
$$

If the social planner insists that the tax schedule be increasing, then the unique solution to $\left(\mathrm{P}_{n}\right)$ is $t^{*}=(1, \ldots, 1 ; 1, \ldots, 1)$. Therefore, in the following we just assume that $\left(\omega_{L}, \omega_{H}\right) \in \Omega_{1}$.

30 Although not provided here, the case in which $\omega_{L}$ is quite small, say 0.05 , shows the possibility that $\mathbb{E}(y)$ increases as $p$ increases. This is due to that fact that for a quite small $\omega_{L}$ the increase of $t_{L L}^{*}$ or $t_{H L}^{*}$ as a small $p$ increases (see Figure $4(\mathrm{a})(\mathrm{b})(\mathrm{e})$ or $(\mathrm{f}))$ could increase $\mathbb{E}(y)$.

31 See Appendix A for derivation. 


\subsection{Possibility of First Best Taxation}

First of all, partition $\Omega_{1}$ into

$$
\begin{aligned}
\Omega_{1 A} & =\left\{\left(\omega_{L}, \omega_{H}\right) \in \Omega_{1}: \omega_{H} \leqq 1\right\}, \\
\Omega_{1 B_{i}} & =\left\{\left(\omega_{L}, \omega_{H}\right) \in \Omega_{1} \backslash \Omega_{1 A}: i \omega_{L}+(n-i) \omega_{H}<n \leqq(i-1) \omega_{L}+(n-i+1) \omega_{H}\right\},
\end{aligned}
$$

for $i=1, \ldots, n$. If $\left(\omega_{L}, \omega_{H}\right) \in \Omega_{1 B_{i}}, i=1, \ldots, n$, the first best feasible tax schedule is

$$
\begin{aligned}
t^{F} \in\{ & t \in\left[0, \omega_{L}\right]^{n} \times\left[0, \omega_{H}\right]^{n}: t_{L,(n-1) L, 0 H}=\omega_{L}, t_{H, 0 L,(n-1) H}=1 ; \\
& t_{L,(n-1-k) L, k H}=\omega_{L}, t_{H,(n-k) L,(k-1) H}=\omega_{H}, k=1, \ldots, n-i \\
& \left.(n-k) t_{L,(n-1-k) L, k H}+k t_{H,(n-k) L,(k-1) H}=n, k=n-i+1, \ldots, n-1\right\} .
\end{aligned}
$$

Since

$$
\lim _{p \rightarrow 0} \Delta\left(t^{F} ; p\right)=\left\{\begin{array}{ll}
\log \frac{n}{\omega_{L}+(n-1) \omega_{H}}-\left(1-\omega_{L}\right) & \text { if } i=1 \\
-\left(1-t_{L, 0 L,(n-1) \omega_{H}}^{F}\right) & \text { otherwise }
\end{array}<0,{ }^{32}\right.
$$

there is no $\left(\omega_{L}, \omega_{H}\right) \in \Omega_{1 B_{i}}$ for $i=1, \ldots, n$ such that the first best feasible tax schedule $t^{F}$ can be the solution to $\left(\mathrm{P}_{n}\right)$ for every $p \in(0,1)$. Also, it turns out that the polynomial equation $\Delta\left(t^{F} ; p\right)=0$ of $p$ may have multiple roots so that it is impossible to define the unique $\bar{\rho}$ such that $\Delta\left(t^{F} ; p\right) \geqq 0$ for $p \geqq \bar{\rho}$.

Now, suppose that $\left(\omega_{L}, \omega_{H}\right) \in \Omega_{1 A}$. In this case, the unique first best feasible tax schedule is

$$
t^{F}=\left(\omega_{L}, \ldots, \omega_{L} ; \omega_{H}, \ldots, \omega_{H}\right) .
$$

To find the condition under which $t^{F}$ is the solution to $\left(\mathrm{P}_{n}\right)$, consider the (IC) constraint at $t^{*}:{ }^{33}$

$$
\begin{aligned}
\Delta\left(t^{F} ; p\right)= & \sum_{j=0}^{n-1}{ }_{n-1} C_{j} p^{n-1-j}\left[\sum_{k=0}^{n-j}(-1)^{k+\bmod (n-1-j, 2)}{ }_{n-j} C_{k} \log \left(k \omega_{L}+(n-k) \omega_{H}\right)\right] \\
& -\left(\omega_{H}-\omega_{L}\right),
\end{aligned}
$$

where $\bmod (x, 2)$ is 0 if $x$ is even and 1 if $x$ is odd.

Lemma 5.1 For all $n \geqq 2$ and all $j=0, \ldots, n-2, \Delta\left(t^{F} ; p\right)$ is strictly increasing in $p^{n-1-j}$.

Proof: See Appendix C.

For $\left(\omega_{L}, \omega_{H}\right) \in \Omega_{1 A}$, define $\bar{\rho} \in \overline{\mathbb{R}}$ by $\Delta\left(t^{F} ; \bar{\rho}\right)=0$, and let $\widehat{\rho}=\min \{1, \bar{\rho}\}$. Define also

$$
\Omega^{F}=\left\{\left(\omega_{L}, \omega_{H}\right) \in \Omega_{1 A}: \lim _{p \rightarrow 0} \Delta\left(t^{F} ; p\right)=\log \frac{n \omega_{H}}{\omega_{L}+(n-1) \omega_{H}}-\left(\omega_{H}-\omega_{L}\right) \geqq 0\right\} .
$$

Proposition 5.2 If $p \geqq \widehat{\rho}$, then the first best feasible tax schedule $t^{F}$ is the unique solution to $\left(P_{n}\right)$. In particular, if $\left(\omega_{L}, \omega_{H}\right) \in \Omega^{F}$, then $t^{F}$ is the unique solution to $\left(P_{n}\right)$ for all $p \in(0,1)$.

32 To see that $\log \frac{n}{\omega_{L}+(n-1) \omega_{H}}-\left(1-\omega_{L}\right)<0$ for $\left(\omega_{L}, \omega_{H}\right) \in \Omega_{2_{1}}$, note that $d($ LHS $) / d \omega_{L}>0$. Since $\omega_{L}<n-(n-1) \omega_{L}$ in $\Omega_{1 B_{1}}$, it follows that LHS $<\lim _{\omega_{L} \rightarrow n-(n-1) \omega_{H}} \log \frac{n}{\omega_{L}+(n-1) \omega_{H}}-\left(1-\omega_{L}\right)=(n-1)\left(1-\omega_{H}\right)<0$.

33 See Appendix B for derivation. 
Proof: Same as the proof of Proposition 3.2.

Corollary $5.3 \lim _{n \rightarrow \infty} \Omega^{F}=\varnothing$.

Proof: Since $\lim _{n \rightarrow \infty} \lim _{p \rightarrow 0} \Delta\left(t^{F} ; p\right)=-\left(\omega_{H}-\omega_{L}\right)<0$, we have the result.

The intuition of this result is that as the number of agents increases, the incentive for a rich agent to misreport his type increases because the possibility that too little public good is provided decreases. Thus, it becomes more difficult to satisfy the (IC) constraint and finally the possibility of first best feasible tax schedule gets to disappear.

\subsection{Second Best Feasible Tax Schedule}

The same result as Lemma 3.3 holds for $n>2$.

Proposition 5.4 Suppose that a tax schedule $t^{*}$ is a solution to $\left(P_{n}\right)$. Then,

$$
t_{H, 0 L,(n-1) H}^{*}=\min \left\{\omega_{H}, 1\right\} .
$$

Proof: Same as the proof of Lemma 3.3.

On the contrary, the result like Lemmas 3.5 does not hold for $n>2$. Nonetheless, we can find a similar result with a mild assumption.

Proposition 5.5 Suppose that a tax schedule $t^{*}$ is a solution to $\left(P_{n}\right)$. For each $j \in\{1, \ldots, n-1\}$, if $t_{H, j L,(n-1-j) H}^{*}>0$, then

$$
t_{L,(j-1) L,(n-j) H}^{*}=\omega_{L}
$$

Proof: If $\omega_{L}=0$, then the claim is obvious. Thus, assume that $\omega_{L}>0$. Suppose by way of contradiction that $t_{L,(j-1) L,(n-j) H}^{*}<\omega_{L}$. Choose $\varepsilon$ such that

$$
0<\varepsilon \leqq \min \left\{\omega_{L}-t_{L,(j-1) L,(n-j) H}^{*}, t_{H, j L,(n-1-j) H}^{*}\right\} .
$$

Consider another tax schedule $t^{\prime}$ which replaces $t_{L,(j-1) L,(n-j) H}^{*}$ and $t_{H, j L,(n-1-j) H}^{*}$ in $t^{*}$ by

$$
t_{L,(j-1) L,(n-j) H}^{\prime}=t_{L,(j-1) L,(n-j) H}^{*}+\frac{\varepsilon}{j}, \text { and } t_{H, j L,(n-1-j) H}^{\prime}=t_{H, j L,(n-1-j) H}^{*}-\frac{\varepsilon}{n-j},
$$

respectively. Then, it follows that

$$
\begin{aligned}
U_{i}\left(\omega_{H} \mid \omega_{H}, t^{\prime}\right) & =U_{i}\left(\omega_{H} \mid \omega_{H}, t^{*}\right)+{ }_{n-1} C_{j} p^{j}(1-p)^{n-1-j}\left(\frac{\varepsilon}{n-j}\right) \\
& >U_{i}\left(\omega_{L} \mid \omega_{H}, t^{*}\right) \\
& =U_{i}\left(\omega_{L} \mid \omega_{H}, t^{\prime}\right)+{ }_{n-1} C_{j-1} p^{j-1}(1-p)^{n-j}\left(\frac{\varepsilon}{j}\right) \\
& >U_{i}\left(\omega_{L} \mid \omega_{H}, t^{\prime}\right),
\end{aligned}
$$

which implies that $\Delta\left(t^{\prime} ; p\right)>0$. Since $\Delta(t ; p)$ is continuous in $t_{H, j L,(n-1-j) H}$ we can choose $\delta \in$ $(0, \varepsilon)$ such that a new tax schedule $t^{\prime \prime}$, which replaces $t_{H, j L,(n-1-j) H}^{\prime}$ in $t^{\prime}$ by $t_{H, j L,(n-1-j) H}^{\prime \prime}=$ 
$t_{H, j L,(n-1-j) H}^{\prime}+\frac{\delta}{n-j}$, satisfies (IC). Note that $t^{\prime \prime}$ also satisfies (Feasibility) by its construction, and that

$$
j t_{L,(j-1) L,(n-j) H}^{\prime \prime}+(n-j) t_{H, j L,(n-1-j) H}^{\prime \prime}>j t_{L,(j-1) L,(n-j) H}^{*}+(n-j) t_{H, j L,(n-1-j) H}^{*} .
$$

Thus, we have $W\left(t^{\prime \prime} ; p\right)>W\left(t^{*} ; p\right)$, a contradiction to the hypothesis that $t^{*}$ is a solution.

This result implies that if the tax payment of rich agents is at least positive, poor agents have to pay $100 \%$ tax in the optimal feasible taxation scheme. Thus, the same interpretation as for the two-agent case applies; the optimal feasible tax schedule imposes the burden caused by the rich agents' informational rents on poor agents as much as possible. Also, it is possible that the tax payment of rich agents is absolutely less than that of poor agents since the optimal feasible tax schedule may not be increasing. ${ }^{34}$ Therefore, as the number of agents increases, the regressiveness of optimal feasible tax mechanism could be worse.

Furthermore, in addition to the above positivity assumption, if we assume that the tax schedule must be increasing and $t_{H,(n-1) L, 0 H} \geqq \omega_{L}$, we can show that the same result as Lemma 3.5 for $n>2$. However, even if we restrict the domain of tax mechanism by those assumptions, it is virtually impossible to describe the optimal feasible tax schedule for $n>2$ due to not only too many corner solutions but also the high dimensionality of social planner's problem. In the next section, we study the case in which there is a continuum of agents in the economy.

\section{$5.3 n=\infty$}

Suppose that there are infinitely many agents in the economy. With no loss of generality, we normalize the set of agents as $N=[0,1]$. In this case, a tax schedule can be expressed by $t_{\infty}=$ $\left(t_{L, \infty}, t_{H, \infty}\right)$ where for example $t_{L, \infty}$ is the tax payment of agent $i \in N$ when he reports $\omega_{L}$. Since $\operatorname{Pr}\left(\omega_{j}=\omega_{L}\right)=p$ for all $j \in N$, the expected utility of agent $i$ when his endowment is $\omega_{H}$ is

$$
U_{i}\left(\omega_{H} \mid \omega_{H}, t_{\infty}\right)=\log \left(p t_{L, \infty}+(1-p) t_{H, \infty}\right)+\omega_{H}-t_{H, \infty}
$$

if he reports $\omega_{H}$, and

$$
U_{i}\left(\omega_{L} \mid \omega_{H}, t_{\infty}\right)=\log \left(p t_{L, \infty}+(1-p) t_{H, \infty}\right)+\omega_{H}-t_{L, \infty}
$$

if he reports $\omega_{L}$. Thus, given $\left(\omega_{L}, \omega_{H}\right) \in \Omega$ and $p \in(0,1)$, the social planner's problem is

$$
\max _{t_{\infty}} W\left(t_{\infty} ; p\right)=\log \left(p t_{L, \infty}+(1-p) t_{H, \infty}\right)-\left(p t_{L, \infty}+(1-p) t_{H, \infty}\right)
$$

$\left(\mathrm{P}_{\infty}\right)$

$$
\text { subject to }
$$

$$
\begin{aligned}
& \text { (IC) } \quad t_{L, \infty} \geqq t_{H, \infty} \\
& \text { (Feasibility) }\left(t_{L, \infty}, t_{H, \infty}\right) \in\left[0, \omega_{L}\right] \times\left[0, \omega_{H}\right] .
\end{aligned}
$$

For $\left(\omega_{L}, \omega_{H}\right) \in \Omega_{2}$, the optimal feasible tax schedule is

$$
t_{\infty}^{*} \in\left\{\left(t_{L, \infty}, t_{H, \infty}\right) \in\left[0, \omega_{L}\right] \times\left[0, \omega_{H}\right]: p t_{L, \infty}+(1-p) t_{H, \infty}=1, t_{L, \infty} \geqq t_{H, \infty}\right\} .
$$

34 For the three-agent case, we can show that there exists a non-increasing optimal feasible tax schedule under the positivity assumption of rich agents' tax payment. 
If the social planner insists that the tax schedule be increasing, then the unique second best feasible tax schedule is

$$
t_{\infty}^{*}=\left(t_{L, \infty}^{*}, t_{H, \infty}^{*}\right)=(1,1)
$$

Proposition 5.6 For $\left(\omega_{L}, \omega_{H}\right) \in \Omega_{1}$, the unique optimal feasible tax schedule is

$$
t_{\infty}^{*}=\left(t_{L, \infty}^{*}, t_{H, \infty}^{*}\right)=\left(\omega_{L}, \omega_{L}\right)
$$

Proof: Straightforward.

This result implies that there is no way to prevent a rich agent from lying if $t_{H, \infty}$ is greater than $t_{L, \infty}$, so that imposing $\omega_{L}$ on every agent is optimal for $n=\infty$. Note that the poor agent's tax rate is always $100 \%$, but the rich agent's is strictly less than $100 \%$.

\section{Concluding Remarks}

In this paper, we consider the feasible taxation problem of a public good economy from an efficiency point of view. Using a Bayesian mechanism design approach, we fully characterized the optimal feasible tax mechanism for an economy with two agents, and conducted some comparative statics analyses of the mechanism. Also, we provided some partial characterization results for the case of more than two agents. These characterization results show how the optimal tax mechanism deals with the incentive or free-riding problem of the economy and the (individual) feasibility constraint simultaneously. In the following, we will discuss some extensions of this study.

In this paper, we assumed that the social welfare is the sum of the agents' utilities. However, if we assume another form of social welfare functions such as weighted sum of the agents' utilities or Rawlsian welfare function, then finding an optimal feasible tax mechanism would be a quite difficult problem because we are no longer able to reduce the dimension of the social planner's problem. By nature, the feasibility constraint renders the optimal tax mechanism to have many corner solutions so that the high dimensionality of the problem will produce so many cases we have to handle.

Our optimal feasible tax mechanism is not renegotiation-proof. Consider for example of Figure 3(d). If two agents are both poor, then each one's tax payment is $t_{L L}^{*} \approx 0.21<0.25=\omega_{L}$. Thus, after the optimal taxation, they have an ex-post incentive to renegotiate for increasing the underprovided public good since the marginal benefit from the increase in public good is greater than the marginal cost, -1 . In this case, we can easily make our optimal feasible tax mechanism renegotiation-proof by imposing a constraint that $t_{L L}^{*}=\omega_{L}$ if $\omega_{L} \leqq 1 / 2$ and $t_{L L}^{*}>1 / 2$ if $\omega_{L}>1 / 2$. Note that this renegotiation-proofness decreases $t_{H L}^{*}$ for some cases.

Finally, we may consider the model with more than two types. If a continuous type space is employed for each agent, we have to deal with the (IC) constraint which has a form of partial differential equation or inequality. Unfortunately, the standard differential approach used in mechanism design literature (e.g., Laffont and Maskin [1979]) is not applicable to this case. Thus, it is an open question in the future research how to transform such a partial differential equation suitable to the social planner's objective function. 


\section{References}

[1] Andreoni, James, (1998), "Toward a Theory of Charitable Fund-Raising," Journal of Political Economy 106, 1186-1213.

[2] d'Aspremont, C. and L.-A. Gérard-Varet, (1979) "Incentives and Incomplete Information," Journal of Public Economics 11, 25-45.

[3] Bergstrom, Theodore, Larry Blume, and Hal Varian, (1986), "On the Private Provision of Public Goods," Journal of Public Economics 29, 25-49.

[4] Clarke, E. H., (1971), "Multipart Pricing of Public Goods," Public Choice 2, 19-33.

[5] Corless, Robert M., G. H. Gonnet, D. E. G. Hare, D. J. Jeffrey, and D. E. Knuth, (1996), “On the Lambert W Function," Advances in Computational Mathematics, 5, 329-359.

[6] Dagan, N., R. Serrano, and O. Volij, (1999), "Feasible Implementation of Taxation Methods," Review of Economic Design 4, 57-72.

[7] Gradstein, Mark, (1994), "Efficient Provision of a Discrete Public Good," International Economic Review 35, 877-897.

[8] Groves, Theodore, (1973), "Incentives in Teams," Econometrica 41, 617-631.

[9] Groves, T. and J. Ledyard, (1987), "Incentive Compatibility since 1972," Information, Incentives and Economic Mechanisms: Essays in Honor of Leonid Hurwicz, edited by T. Groves, R. Radner and S. Reiter, University of Minnesota Press.

[10] Guesnerie, Roger, (1995), A Contribution to the Pure Theory of Taxation, Cambridge University Press.

[11] Hong, Lu, (1996), "Bayesian Implementation in Exchange Economies with State Dependent Feasible Sets and Private Information," Social Choice and Welfare 13, 433-444.

[12] Hong, Lu, (1998), "Feasible Bayesian Implementation with State Dependent Feasible Sets," Journal of Economic Theory 80, 201-221.

[13] Hurwicz, Leonid, (1972), "On Informationally Decentralized Systems," in Decision and Organization: A Volume in Honor of Jacob Marschak, Ch. 14, edited by R. Radner and C. B. McGuire, North-Holland Publishing Co.

[14] Hurwicz, Leonid, Eric Maskin, Andrew Postlewaite, (1995), "Feasible Nash Implementation of Social Coice Rules When the Designer does not Know Endowments or Production Sets," in The Economics of Informational Decentralization, Complexity, Efficiency and Stability, Ch. 14, edited by J. Ledyard, Kluwer Academic Publishers.

[15] Jackson, Matthew, O., (2001), "A Crash Course in Implementation Theory," Social Choice and Welfare 18, 655-708. 
[16] Jackson, Matthew, O., (2003), "Mechanism Theory," in Optimization and Operations Research, edited by Ulrich Derigs, in the Encyclopedia of Life Support Systems, EOLSS Publishers: Oxford UK, [http://www.eolss.net].

[17] Laffont, Jean-Jacques and Eric S. Maskin (1979), "A Differential Approach to Expected Utility Maximizing Mechanisms," in Aggregation and Revelation of Preferences, Ch. 16, edited by Jean-Jacques Laffont, North-Holland Publishing Co.

[18] Ledyard, John O. and Thomas R. Palfrey, (1999), "A Characterization of Interim Efficiency with Public Goods," Econometrica 67, 435-448.

[19] Maskin, Eric S., (1999), "Nash Equilibrium and Welfare Optimality," Review of Economic Studies 66, 23-38.

[20] Maskin, Eric S. and T. Sjöström (2002), "Implementation Theory," Handbook of Social Choice and Welfare, vol. I, Ch. 5, edited by K. J. Arrow, A. K. Sen and K. Suzumura, Elsevier Science Ltd.

[21] Mirrlees, James A., (1971), "An Exploration in the Theory of Optimum Income Taxation," Review of Economic Studies 38, 175-208.

[22] Myerson, Roger B., (1989), "Incentive Compatibility and the Bargaining Problem," Econometrica 47, 61-73.

[23] Palfrey, Thomas R., (2002), "Implementation Theory," in Handbook of Game Theory, vol. III, Ch. 61, edited by R. Aumann and S. Hart, Elsevier Science Ltd.

[24] Rhee, Byungchae, (2004), "Immigration Incentives," Mimeo.

[25] Stiglitz, Joseph E., (1987), "Pareto Efficient and Optimal Taxation and the New New Welfare Economics," Handbook of Public Economics, vol. II, Ch. 15, edited by Alan J. Auerbach and Martin Feldstein, Elsevier Science Ltd.

[26] Tian, Guoqiang, (1999), "Bayesian Implementation in Exchange Economies with State Dependent Preferences and Feasible Sets," Social Choice and Welfare 16, 99-119. 


\section{Appendix}

\section{A Derivation of Equation (7)}

$$
\begin{aligned}
\Delta\left(t^{F} ; p\right) & =\sum_{j=0}^{n-1}{ }_{n-1} C_{j} p^{j}(1-p)^{n-1-j}\left(t_{L, j L,(n-1-j) H}^{F}+t_{H, j L,(n-1-j) H}^{F}\right) \\
& =\sum_{j=1}^{n-1}\left[{ }_{n-1} C_{j-1} p^{j-1}(1-p)^{n-j}\left(t_{L,(j-1) L,(n-j) H}^{F}-1\right)+{ }_{n-1} C_{j} p^{j}(1-p)^{n-1-j}\left(1-t_{H, j L,(n-1-j) H}^{F}\right)\right] \\
& =\sum_{j=1}^{n-1}\left[{ }_{n-1} C_{j-1} p^{j-1}(1-p)^{n-j}\left(t_{L,(j-1) L,(n-j) H}^{F}-1\right)+{ }_{n-1} C_{j} p^{j}(1-p)^{n-1-j}\left(\frac{j}{n-j}\right)\left(t_{L,(j-1) L,(n-j) H}^{F}-1\right)\right] \\
& =\sum_{j=1}^{n-1}{ }_{n-1} C_{j-1} p^{j-1}(1-p)^{n-1-j}\left(t_{L,(j-1) L,(n-j) H}^{F}-1\right) .
\end{aligned}
$$

\section{B Derivation of Equation (8)}

$$
\begin{aligned}
\Delta\left(t^{F} ; p\right) & =\sum_{j=0}^{n-1}{ }_{n-1} C_{j} p^{j}(1-p)^{n-1-j}\left[\log \left(\frac{j \omega_{L}+(n-j) \omega_{H}}{(j+1) \omega_{L}+(n-1-j) \omega_{H}}\right)-\left(\omega_{H}-\omega_{L}\right)\right] \\
& =\sum_{j=0}^{n-1}{ }_{n-1} C_{j} p^{j}(1-p)^{n-1-j} \log \left(\frac{j \omega_{L}+(n-j) \omega_{H}}{(j+1) \omega_{L}+(n-1-j) \omega_{H}}\right)-\left(\omega_{H}-\omega_{L}\right)(p+(1-p))^{n-1} \\
& =\sum_{j=0}^{n-1}{ }_{n-1} C_{j} p^{n-1-j}\left[\sum_{k=0}^{n-j}(-1)^{k+\bmod (n-1-j, 2)}{ }_{n-j} C_{k} \log \left(k \omega_{L}+(n-k) \omega_{H}\right)\right]-\left(\omega_{H}-\omega_{L}\right),
\end{aligned}
$$

To see that the third equality holds, consider the coefficient of $p^{n-1-j}, j=0, \ldots, n-1$. Suppose $(n-1-j)$ is even. Then, the coefficient is

$$
\begin{aligned}
&\left({ }_{n-1} C_{0} \cdot{ }_{n-1} C_{n-1-j}\right)\left[\log \left(n \omega_{H}\right)-\log \left(\omega_{L}+(n-1) \omega_{H}\right)\right] \\
&-\left({ }_{n-1} C_{1} \cdot{ }_{n-2} C_{n-2-j}\right)\left[\log \left(\omega_{L}+(n-1) \omega_{H}\right)-\log \left(2 \omega_{L}+(n-2) \omega_{H}\right)\right] \\
&+\left({ }_{n-1} C_{2} \cdot{ }_{n-3} C_{n-3-j}\right)\left[\log \left(2 \omega_{L}+(n-2) \omega_{H}\right)-\log \left(3 \omega_{L}+(n-3) \omega_{H}\right)\right] \\
& \vdots \\
&+\left({ }_{n-1} C_{n-1-j} \cdot{ }_{j} C_{0}\right)\left[\log \left((n-1-j) \omega_{L}+(j+1) \omega_{H}\right)-\log \left((n-j) \omega_{L}+j \omega_{H}\right)\right] \\
&=\left({ }_{n-1} C_{0} \cdot{ }_{n-1} C_{j}\right) \log \left(n \omega_{H}\right)-\left({ }_{n-1} C_{j} \cdot{ }_{j} C_{0}\right) \log \left((n-j) \omega_{L}+j \omega_{H}\right) \\
& \quad+\sum_{k=1}^{n-j-1}(-1)^{k}\left({ }_{n-1} C_{k-1} \cdot{ }_{n-k} C_{j}+{ }_{n-1} C_{k} \cdot{ }_{n-k-1} C_{j}\right) \log \left(k \omega_{L}+(n-k) \omega_{H}\right) \\
&=\left({ }_{n-1} C_{0} \cdot{ }_{n-1} C_{j}\right) \log \left(n \omega_{H}\right)-\left({ }_{n-1} C_{j} \cdot{ }_{j} C_{0}\right) \log \left((n-j) \omega_{L}+j \omega_{H}\right) \\
& \quad+\sum_{k=1}^{n-j-1}(-1)^{k+1}\left({ }_{n-1} C_{j} \cdot{ }_{n-j} C_{k}\right) \log \left(k \omega_{L}+(n-k) \omega_{H}\right) \\
&={ }_{n-1} C_{j} \sum_{k=0}^{n-j}(-1)^{k}{ }_{n-j} C_{k} \log \left(k \omega_{L}+(n-k) \omega_{H}\right) .
\end{aligned}
$$


A similar calculation shows that when $(n-1-j)$ is odd the coefficient is the same.

\section{Proof of Lemma 5.1}

Proof: Let $\xi_{n, j}\left(\omega_{L}, \omega_{H}\right)=\sum_{k=0}^{n-j}(-1)^{k+\bmod (n-1-j, 2)}{ }_{n-j} C_{k} \log \left(k \omega_{L}+(n-k) \omega_{H}\right)$. First, we want to show that $\xi_{n, j}\left(\omega_{L}, \omega_{H}\right)$ is strictly increasing in $\omega_{H}$. For $j=0, \ldots, n-2$,

$$
\begin{aligned}
& \frac{\partial \xi_{n, j}\left(\omega_{L}, \omega_{H}\right)}{\partial \omega_{H}} \\
= & \frac{\partial}{\partial \omega_{H}}\left(\sum_{k=0}^{n-j}(-1)^{k+\bmod (n-1-j, 2)}{ }_{n-j} C_{k} \log \left(k \omega_{L}+(n-k) \omega_{H}\right)\right) \\
= & \sum_{k=0}^{n-j}(-1)^{k+\bmod (n-1-j, 2)} \frac{(n-k)_{n-j} C_{k}}{k \omega_{L}+(n-k) \omega_{H}} \\
= & (n-1-j) !\left(\omega_{H}-\omega_{L}\right)^{n-1-j}\left[\frac{n}{\prod_{k=0}^{n-1-j}\left(k \omega_{L}+(n-k) \omega_{H}\right)}-\frac{j}{\prod_{k=1}^{n-j}\left(k \omega_{L}+(n-k) \omega_{H}\right)}\right] \\
= & (n-j) !\left(\omega_{H}-\omega_{L}\right)^{n-1-j}\left[\frac{n \omega_{L}}{\prod_{k=0}^{n-j}\left(k \omega_{L}+(n-k) \omega_{H}\right)}\right] \\
> & 0 .
\end{aligned}
$$

Thus, we have for all $n \geqq 2$ and all $j=0, \ldots, n-2$,

$$
\xi_{n, j}\left(\omega_{L}, \omega_{H}\right)>\xi_{n, j}\left(\omega_{L}, \omega_{L}\right)=\log \left(n \omega_{L}\right) \sum_{k=0}^{n-j}(-1)^{k+\bmod (n-1-j, 2)}{ }_{n-j} C_{k}=0
$$

by the Binomial Theorem. It follows that

$$
\frac{\partial \Delta\left(t^{F} ; p\right)}{\partial p^{n-1-j}}={ }_{n-1} C_{j} \xi_{n, j}\left(\omega_{L}, \omega_{H}\right)>0
$$

